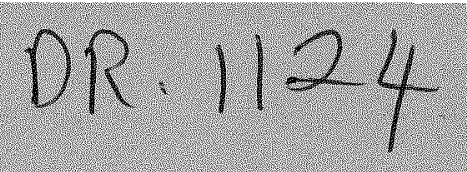

ENICO-1007

\title{
PLUGGING OF AIR-PURGED DIP-TUBE PROBES
}

March 1980

Idaho Falls, Idaho 83401

EXON NUCLEAR IDAHO COMPANY, Inc. 
Printed in the United States of Arnerica

Available from

National Technical Information Service

U.S. Department of Commerce

5285 Polt Royal Road

Springtield, VA 22161

NTIS Price Codes: Printed Copy 403

Microfiche A01

\section{DISCLAIMER}

This book was preoared as an account of work sponsored by an agency of the United States Government Neither the United States Government nor any agency thereof: nor any of their emplovees, makes any warranty, express or implied or assumes any legal liabilty or responsibility for the accuracy completeness, or usefulness of any information, apparatus, product or process disctosed, of represents that its use would rot infringe privately owned rights. Peferences herein to any specific commerclal product, process, or service by trade name tracemank, manufacturer, or otherwise. does not necessariy constiute or mply its endorsement, teconimendation, or favoning by the United States Government or any agehcy thereof. The views and opintens of authots expressed herein do not necessanily state or reflect those of the Uniled States Government or any agency thereof. 


\section{DISCLAIMER}

Portions of this document may be illegible in electronic image products. Images are produced from the best available original document. 
ENIC0-1007

\author{
Distributed Under Category \\ UC-70 \\ Nuclear Waste Management
}

PLUGGING OF AIR-PURGED DIP-TUBE PROBES

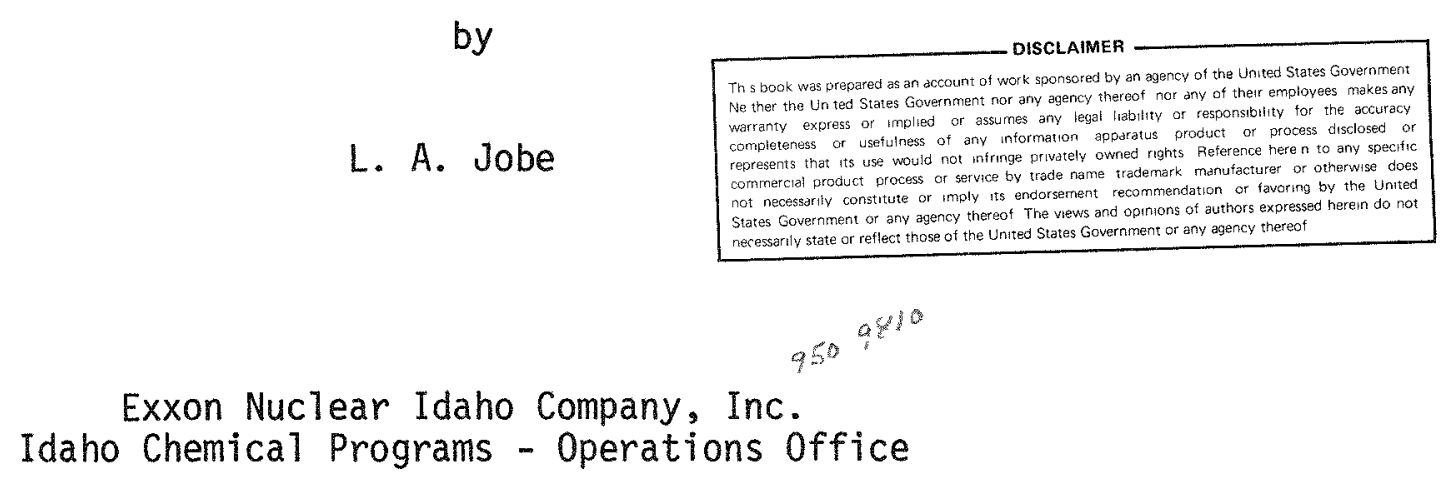

Date Published - March 1980

Prepared for the

Department of Energy

Idaho Operations Office

Under Contract DE-AC07-79ID01675 
ABSTRACT

Results of a task to determine the variables affecting air-purged, dip-tube probe plugging is described. Variables studied were probe tip shape, purge rate, probe size, solution depth, effect of humidification and type of solution. Six different solutions were tested. Recommended design criteria for probe installation are presented. 


\section{SUMMARY}

Although probe plugging is a common operational problem in remotely operated nuclear fuel reprocessing plants, almost no work related to probe plugging has previously been reported. At the Idaho Chemical Processing Plant (ICPP), a laboratory study using a 14-cm diameter glass vessel was conducted to determine the variables affecting the frequency of plugging of air-purged dip-tube probes and ways of cleaning plugged probes. Liquid levels, solution densities, and fluidized-bed densities are determined by the purged-probe method in reprocessing plants.

A survey of the location of instruments at the ICPP having frequent plugging problems suggested six typical solutions to be studied: concentrated third-cycle raffinate (aluminum nitrate), waste calciner feed, storage tank wastes, borated cooling water, process equipment wastes, and Fluorinel dissolver solution. The effect of probe tip shape, purge rate, humidification of purge gas, probe size, and liquid depth on plugging frequency were studied in the aluminum nitrate raffinate solution by simultaneous testing of up to six vertical and two horizontal probes at temperatures up to boiling. Selected probes and physical conditions were then used for a single test in each of the other solutions.

Test results showed the plugging rate was less with: 1) the $V$-notch probe-tip design, 2) reduction of purge rate, 3 ) humidification of the purge gas, and 4) increased size of probes. Liquid depth did not have any definitive effect. Humidifying the purge gas was the most effective method of reducing plugging in a crystallizing type solution. Nearly complete plugging of a probe is required to raise the measured back pressure.

All plugs were reasonably soluble in distilled water; plugs found in the plant equipment usually are not as soluble due to the presence of insoluble fissium solids or precipitates from unstable solutions in the plant. Clearing plugs in the plant generally requires full instrument air pressure $(140 \mathrm{kPa})$, high pressure water, or nitric acid washes from a mini-pump that can deliver up to $6900 \mathrm{kPa}$ (1000 psi) pressure.

General design recommendations for improved probe operation for plugging type applications include: 1) use of vertical rather than horizontal probes, 2) using an inverted $V$-notch probe tip, 3) having a 3/4-inch pipe diameter by $100-\mathrm{mm}$ long probe welder to a 1/4-inch pipe purge gas supply line, 4) using low purge rates of $100 \mathrm{sml} / \mathrm{min}(0.2 \mathrm{scfh})$ or $1 \mathrm{ess}, 5)$ humidification of purge air, especially for crystallizing type solutions, and 6) maintaining the temperature of a solution above its crystallization temperature. 


\section{CONTENTS}

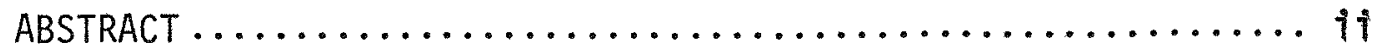

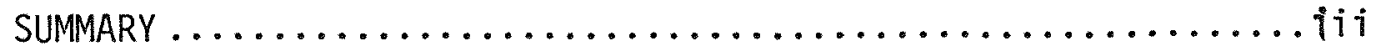

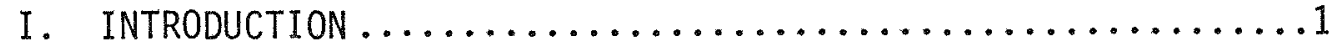

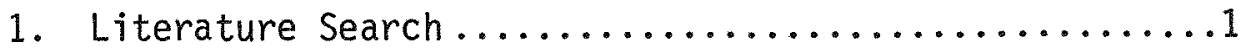

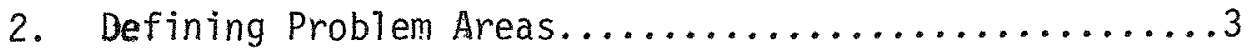

II. EXPERIMENTAL APPARATUS AND PROCEDURE $\ldots \ldots \ldots \ldots \ldots \ldots \ldots$

1. Experimental Apparatus .................... 6

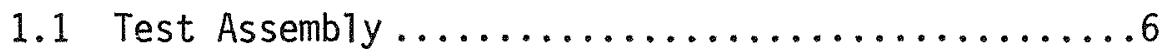

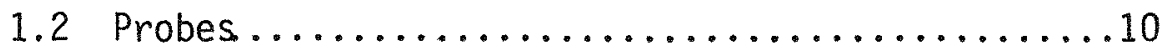

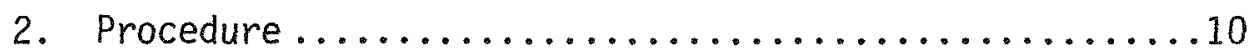

2.1 Plugging Tests ........................ 10

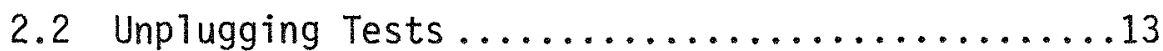

III. RESULTS AND DISCUSSION ........................... 14

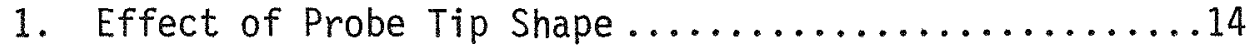

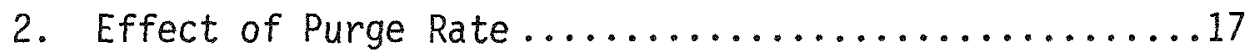

3. Effect of Humidifying Purge Gas ................ 17

4. Effect of Probe Size ......................20

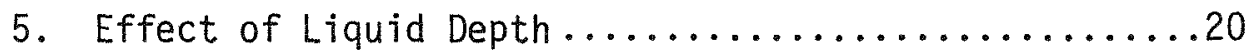

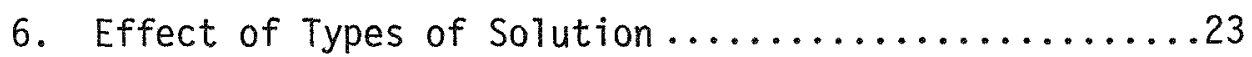

6.1 Acid Deficient Aluminum Nitrate Batch Evaporator

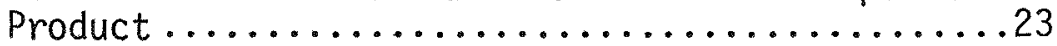

6.2 Low Fluoride Sodium-Zirconium Blend Waste Calciner

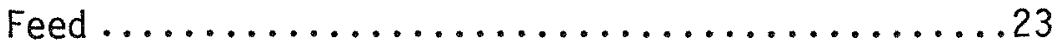

6.3 High Fluoride Zirconium Waste Calciner Feed ....23

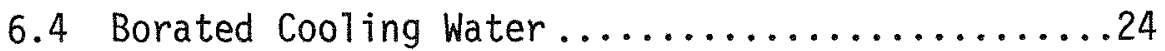

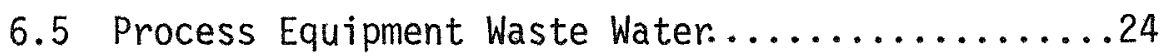

6.6 Complexed Fluorinel Dissolver Product.........27

7. Unplugging Studies . . . . . . . . . . . . . . . 27

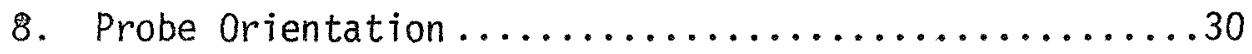

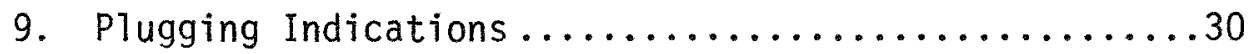

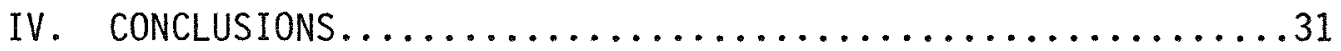

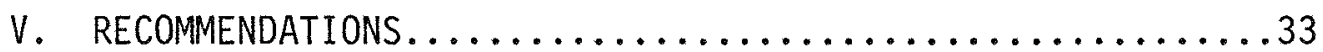

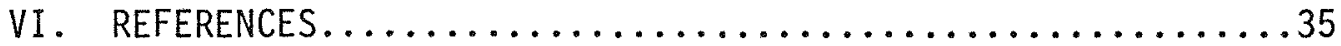


CONTENTS

(continued)

FIGURES

1. Probe Test Apparatus ............................

2. Probe Test Apparatus Detai1s ......................

3. Purge Rotameter Panel and Overal1 Assembly............9

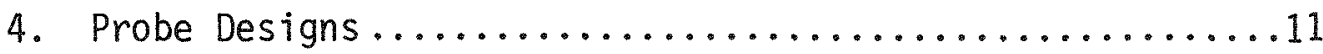

5. Plugs of Different Probe Tip Shapes .................. 15

6. Effect of Purge Rate upon Plugging Frequency...........19

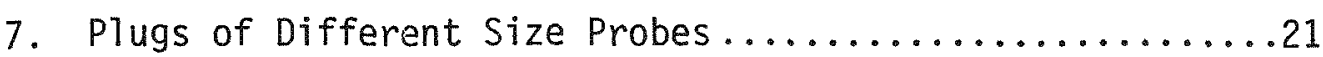

8. Effect of Probe Size upon Plugging Time..............22

9. High Fluoride Zirconium Waste Calciner Feed............25

a. STudge Pattern after Draining Vesse1

b. Partial Probe Plugs after Draining Vesse]

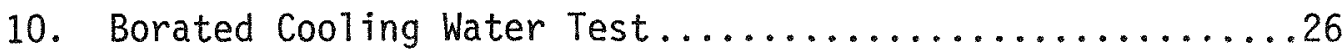

a. Effect of Probe Size on Plugging with $6 \mathrm{~g} \mathrm{~B} / \mathrm{L}$

b. Effect of Probe Size on Plugging with $8 \mathrm{~g} \mathrm{~B} / \mathrm{L}$

11. Effect of Probe Size on Plugging with Concentrated PEW Evaporator Product............................28

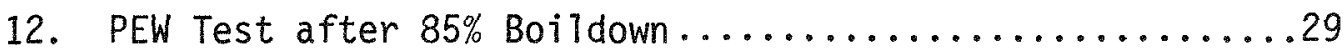

a. Plan View of Scales in Vesse1

b. Scale and Sludge Samples

TABLES

I. Plant Areas Having Probe Plugging Problems............4

II. Solution Compositions at Typical Problem Areas for Plugged Probes..................................... 5

III. Probe Plugging Frequency of Various Probe Shapes........16

IV. Effect of Purge Rate and Orientation on Plugging Rates..18 


\section{INTRODUCTION}

One of the most common operational problems in nuclear fuel reprocessing plants is partial and total plugging of air-purged, dip-tube probes, which are generally used to determine liquid level and solution or fluidized-bed densities. The purpose of this task was to determine the variables that affect the frequency or rate of plugging of probes and to identify effective methods of removing such plugs. The variables studied were: probe tip shape, purge rate, humidification of purge gas, probe size, liquid depth, and type of solution.

Measuring 1iquid level and density by purged probes was adopted by a11 radiochemical processing plants because of its simplicity, lack of moving parts, easy installation, small space requirements, and overall reliability. However, there are disadvantages to the system: loss of precision can result from fouling of tubes due to crystallization and from dip tube bias caused by surface tension and density effects of the fluid upon bubble formation, especially for non-symmetrical (e.g. single tube) systems. Greater precision can be achieved by using the two-tube system for each probe: one line is used to supply the purge gas and a separate non-flow line is used to conduct the back-pressure signal to the transducer. Inherent pressure pulsations from bubbler systems can be reduced by damping or averaging the signal, but at a sacrifice in dynamic response.

\section{Literature Search}

A. L. Ayers (then at ICPP) stated ${ }^{1}$ that clogging of dip tubes of ICPP evaporators could be avoided by better control, such as control of steam to dip-tubes from density measuring systems. He stated, however, that humidification was found to be unnecessary and considered the use of steam dangerous for clearing probe plugs because of the risk of backflow of radioactive solutions into nonradioactive zones. De-clogging by higher pressure air, water, or nitric acid were identified as preferable to the use of steam.

Challe and Freiwald ${ }^{2}$ of Eurochemic studied plugging of probes, although their primary emphasis was on the main causes of errors and in the dynamic behavior of dip tubes. Crystallization tests showed complete llugging of dip tubes in one to three days, and they felt the only satisfactory way of preventing such fouling was to mix steam with the purge gas to produce a condensate film on the inside of the dip tube. The shape of the probe tip had a definite bearing on precision of readings and amplitude of oscillation; their sixteen probe shapes gave reading errors in 180-mm deep water from 1.5 to $4 \%$, with an error variation of 0.38 to 1.27 depending upon the probe. Damping reduced the oscillation but also reduced the dynamic response. The best shapes, as found by Challe and Freiwald ${ }^{2}$, for minimum oscillation were reduced vertical 
insert tips; the best shapes for precision were conical flare or a 90 degree bend. For a given probe tip shape, purge rate had little or no effect on precision. Their best precision was $2.0-2.3 \%$, which may be adequate for operating conditions, but not for accountability purposes. Pressure drop in 8-mm diameter lines is negligible at purge rates of $14 \mathrm{sL} / \mathrm{hr}(250 \mathrm{smL} / \mathrm{min}$ or $0.5 \mathrm{scfh})$. The shortest permissible distance from the probe tip to vessel bottom was $5 \mathrm{~mm}$. Dynamic response tests showed a level measuring system could be approximated by a second order term with no attenuation at frequencies less than $0.125 \mathrm{Hza}$.

Klitgaard ${ }^{3}$ reported that slurry detection by dip tubes gave reproducible results but that the sensitivity was low and therefore not recommended for radioactive applications.

Kelly, 4 summarizing results of an exhaustive survey at ORNL, discussed the following factors affecting accuracy of dip-tube level and density systems: depth of immersion, specific gravity of fluid, specific gravity of gas, surface tension of fluid, and viscosity of fluid. In a symmetrical system (e.g. two probe density measuring), surface tension and viscosity effects cancel out. Except for high pressure systems, the specific gravity of the gas has negligible effect. For level measuring systems, the effect of viscosity, surface tension, and density of the fluid must be taken into consideration. A bubble rate of not over 30 bubbles per minute was recommended to essentially eliminate viscosity effects.

Back pressure wave forms were given for several probe tip shapes. Although Kelly recommended the square cut tip as having the most uniform wave form, his graphs show a mean back pressure of $18 \mathrm{~mm}$ water for this shape vs. $12.5 \mathrm{~mm}$ for the 45 degree bevel, $10 \mathrm{~mm}$ for the 90 degree notch, $11.5 \mathrm{~mm}$ for the 45 degree notch, and $15 \mathrm{~mm}$ for the peripheral hole designs ${ }^{b}$. For density systems, Kelly recommended not over $30 \mathrm{~m}$ of $3 / 8$-inch tubing for the line, $50 \mathrm{smL} / \mathrm{min}(0.1 \mathrm{scfh})$ purge rate, and $3 / 8$-inch tubing or 1/8-inch pipe for the dip tubes. He stated that level measuring systems with the most careful installation seldom have an error less than $0.75 \%$ of maximum level, but that density measuring systems may be accurate to within $0.33 \%$.

\footnotetext{
author's note: stainless steel probe data showed less back-pressure variation for increasing purge rates than Plexiglass, glass, or brass materials.

b Author's note: the wave patterns show the $45^{\circ}$ notch producing the lowest amplitude, uniform back-pressure wave form.
} 
Long $^{5}$ recommended the same size dip tubes as Kelly, stating that larger tubes are more costly and less accurate, but smaller tubes are more likely to plug. Recommended were: 45 degree bevel tip shape, transmission lines of $3 / 8$ or $1 / 2$-inch tubing not over $35 \mathrm{~m}$ (100 ft) long and purge gas rates of $50 \mathrm{smL} / \mathrm{min}(0.1 \mathrm{scfh})$. Purge gas flows should be balanced for liquid level measurements and the four-tube system used for density measurements; additional accuracy is not warranted except for accountability measurements. Purged dip tubes can measure liquid levels to a sensitivity of $0.6 \%$ fu11-scale (FS) and density to a sensitivity of 0.01 sp.gr. units.

By statistical methods, Bianco ${ }^{6}$ found that the effects of changing specific gravities, levels, and flow rates as well as a gravity level interaction were all significant in measuring liquid levels, giving a standard error of $+2.5 \mathrm{~mm}(0.10 \mathrm{inch})$. In the measurement of specific gravity, only the effects of gravity-level and probe separation-flow rate interactions were significant, giving a standard error of +0.007 sp.gr. units.

Hicks and Jones ${ }^{7}$ determined frictional drop in $17.5 \mathrm{~m}$ (50 ft) of 1/4-inch tubing to be excessive for a $10 \mathrm{smL} / \mathrm{min}(0.02 \mathrm{scfh})$ purge rate to remain within $+0.5 \%$ error, whereas $3 / 8$-inch tubing allowed purge rates up to $150 \mathrm{smL} / \mathrm{min}(0.3 \mathrm{scfh})$. Since purge flows should be kept within 50 $\mathrm{smL} / \mathrm{min}(0.1 \mathrm{scfh})$ of each other, the purge rate should then be approximately $150 \mathrm{smL} / \mathrm{min}(0.3 \mathrm{scfh})^{a}$.

Rose ${ }^{8,9}$ recommended, for accountability points of a chemical processing plant under stringent inventory control, two assemblies of four dip tube probes; he also recommended sensing units and tamper resistance features, with density transmitters calibrated for 1.0-1.3 and 1.3-1.6 sp.gr. ranges rather than a single 1.0-1.6 range; this gave a precision of $0.009 \mathrm{sp} . \mathrm{gr}$. units or $+0.7 \%$. The precision of a two-tube 1 iquid level measurement was $0.6 \%$ FS $(2 \mathrm{~m})$. A four-tube assembly with dual sensing elements, however, is recommended for nuclear material control use. He also recommended limiting probe lines to $35 \mathrm{~m}$ (100 ft) of 3/8-inch tubing from the sensors.

\section{Defining Problem Areas}

To define the problem areas, the Instrument Shop (Maintenance) and Operations personnel were contacted for their comments on specific instruments or areas exhibiting probe plugging problems. These are listed in Table I.

author's note: purge rotameters are now available in the low range of 5-40 smL/min (0.1-0.8 scfh) which would allow lower purge rates to be used. 
TABLE I. PLANT AREAS HAVING PROBE PLUGGing PROBLEMS

Unit

Second and Third-Cycle Raffinate Batch Evaporators

Waste Calciner Feed Tanks

Waste Storage Tanks

Borated Cooling Water

PEW Evaporator

Fluorinel Dissolver

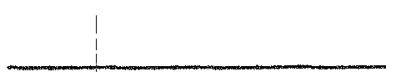

Application

These evaporators concentrate the slightly acid deficient aluminum nitrate raffinate solutions $30 \%$ from 1.5 to $2.3 \mathrm{M} \mathrm{Al}\left(\mathrm{NO}_{3}\right)_{3}$ before sending them to the waste storage tanks.

These tanks receive radioactive waste solutions (e.g. zirconium process raffinate) plus scrub solution plus solid $\mathrm{Ca}\left(\mathrm{NO}_{3}\right)_{2}$ to complex the fluoride ion.

The tanks receive the concentrated wastes from the various stages of processing, with different types of waste going to their specific tanks until calcination.

This tank holds the makeup and circulating boric acid nuclear poison coolant stream for the dissolver heat exchangers.

This vessel concentrates the various dilute wash waste streams in the plant from a sp.gr. near 1.0 to approximately 1.26 before sending them to waste storage tanks.

This solution will be the standard zirconium dissolver product; our tests required complexing the fluoride of this solution with $\mathrm{A} /\left(\mathrm{NO}_{3}\right)_{3}$ to prevent dissolution of the glass test apparatus; complexing is also required to protect SS equipment from severe corrosion.

On the basis of the problem areas listed in Table I, typical solution compositions, specific gravities, and operating temperatures in plant use were determined; these are listed in Table II. All of the solutions listed in Table II, with the exception of that for the waste storage tank, were tested as non-radioactive simulated solutions. 
TABLE II. SOLUTION COMPOSITIONS AT TYPICAL PROBLEM AREAS FOR PLUGGED PROBES

\begin{tabular}{|c|c|c|c|c|c|c|c|c|}
\hline \multirow{2}{*}{ Ion } & \multirow{2}{*}{ Unit } & \multirow{2}{*}{$\begin{array}{r}\text { 3rd Cycle } \\
\text { Raff. Evap. }\end{array}$} & \multirow{2}{*}{$\begin{array}{l}\text { Waste Storage } \\
\text { Tank } \\
\end{array}$} & \multirow{2}{*}{$\begin{array}{c}\text { PEW } \\
\text { Evap. Prod. }\end{array}$} & \multicolumn{2}{|c|}{ Calcine Feed } & \multirow{2}{*}{$\begin{array}{c}\text { Borated } \\
\text { Cooling Water }\end{array}$} & \multirow{2}{*}{$\begin{array}{c}\text { Fluorinel } \\
\text { Comp. Dis. Sol } \\
\end{array}$} \\
\hline & & & & & BTend & Str. Zr. & & \\
\hline U & $g / L$ & $5 \times 10^{-3}$ & & & & & & 1.5 \\
\hline $\mathrm{H}$ & $\mathrm{N}$ & & 1.62 & 1.67 & 0.8 & 1.3 & 1.65 & 2.00 \\
\hline $\mathrm{NO}_{3}$ & M & & 2.32 & 3.28 & 3.3 & 4.27 & & 2.65 \\
\hline $\mathrm{Zr}$ & M & & 0.44 & & 0.19 & 0.50 & & 0.60 \\
\hline A] & M & 2.36 & 0.64 & 0.02 & 0.47 & 0.79 & & 0.33 \\
\hline $\mathrm{F}$ & M & & 3.00 & $4 \times 10^{-3}$ & 1.16 & 3.67 & & 3.06 \\
\hline $\mathrm{NH}_{4}$ & M & 0.25 & & & & & & \\
\hline B & M & 0.50 & 0.19 & 0.003 & 0.086 & 0.25 & 0.55 & \\
\hline $\mathrm{Cd}$ & M & & & & & & & 0.21 \\
\hline $\mathrm{Hg}$ & M & 0.003 & & 0.003 & 0.002 & & & \\
\hline $\begin{array}{l}F e \\
\text { Mn }\end{array}$ & $\begin{array}{l}M \\
M\end{array}$ & & 0.004 & $\begin{array}{l}0.02 \\
0.021\end{array}$ & 0.01 & & & \\
\hline $\mathrm{Ca}$ & M & & & 0.023 & 8.1 & 2.02 & & \\
\hline $\mathrm{Mg}$ & M & & & 0.011 & 0.01 & & & \\
\hline $\mathrm{Na}$ & M & & 0.003 & 1.572 & 0.76 & & & \\
\hline & M & & & 0.125 & 0.28 & & & \\
\hline $\mathrm{PO}_{4}$ & M & & & 0.01 & 0.003 & & & \\
\hline $\mathrm{SO}_{4}$ & $M$ & & & 0.10 & 0.10 & & & 0.056 \\
\hline & M & & 0.0003 & 0.03 & .013 & & & \\
\hline Undis. Sol. & $\mathrm{g} / \mathrm{L}$ & & & 0.03 & & 120 & & \\
\hline $\begin{array}{l}\text { SG } \\
\text { Temp. }\end{array}$ & & $\begin{array}{c}1.385 \\
\text { Boiling } \\
\text { Ambient }\end{array}$ & 1.185 & $\begin{array}{r}1.26 \\
\text { Boiling }\end{array}$ & $\begin{array}{l}1.29 \\
30^{\circ} \mathrm{C}\end{array}$ & $\begin{array}{l}1.36 \\
30{ }^{\circ} \mathrm{C}\end{array}$ & $\begin{array}{c}1.01 \\
30-65^{\circ} \mathrm{C}\end{array}$ & $\begin{array}{l}1.207 \\
75^{\circ} \mathrm{C}\end{array}$ \\
\hline
\end{tabular}




\section{EXPERIMENTAL APPARATUS AND PROCEDURE}

1. Experimental Apparatus

\subsection{Test Assembly}

The overall apparatus and equipment are shown in Figure 1 , the probe mounting assembly in Figure 2, the purge gas distribution and collection panel in Figure 3, and the shapes of the probes chosen for testing in Figure 4.

The condenser in Figure 1 is used to remove and return to the test vessel most of the water vapor leaving the solution being tested, especially under boiling temperature conditions. Replacement of test solution or water vapors was handled through a tee connection at the top of the condenser.

The probe test assembly (Figure 2) was constructed of $155 \mathrm{~mm}$ ( 6 inch) diameter glass tubing for visibility, wrapped with heating wire, and largely insulated to reduce heat loss when operating at near boiling temperatures. It contained provisions for mounting six vertical and two horizontal probes for simultaneous testing of multiple probes. A see-through window section in the insulation was provided near the bottom of the probes, and a mirror was located below the bottom of the glass container for visually observing the progress of plugging. A thermocouple to measure solution temperatures entered the vessel at another of the lower three access ports.

Purge rates to each probe were adjusted through individual purge rotameters, as shown in Figure 3 . When used, humidifiers were placed after the rotameters so that no volume correction was needed for the moisture. The first humidifiers were assembled from laboratory porousplug gas scrubber cylinders, filled with a light cellulose packing and containing about $2.5 \mathrm{~cm}$ of free water at the bottom. The last humidifiers used were commercial bubblers (Meriam model 93155).

Level measurements were made by both pneumatic and electronic differential pressure $(d / p)$ cells connected to recorders for measurement of the change in the liquid level. The differential pressure measurements were of the back pressure existing in the various probe connections downstream of the individual rotameters which controlled the purge rate to each probe, as shown in Figure 3. It was also possible to measure any one of these pressures with a Magnehe Tic gage.

The effect of liquid depth was determined in a 57-mm diameter $\times 132-\mathrm{cm}$ high Plexiglass tube, with a rubber stopper in the bottom for easy removal of solution and crystals. Two SS probes of $3 / 8$-inch tubing were introduced into the top of the tube, with the bottom of the tubes being 


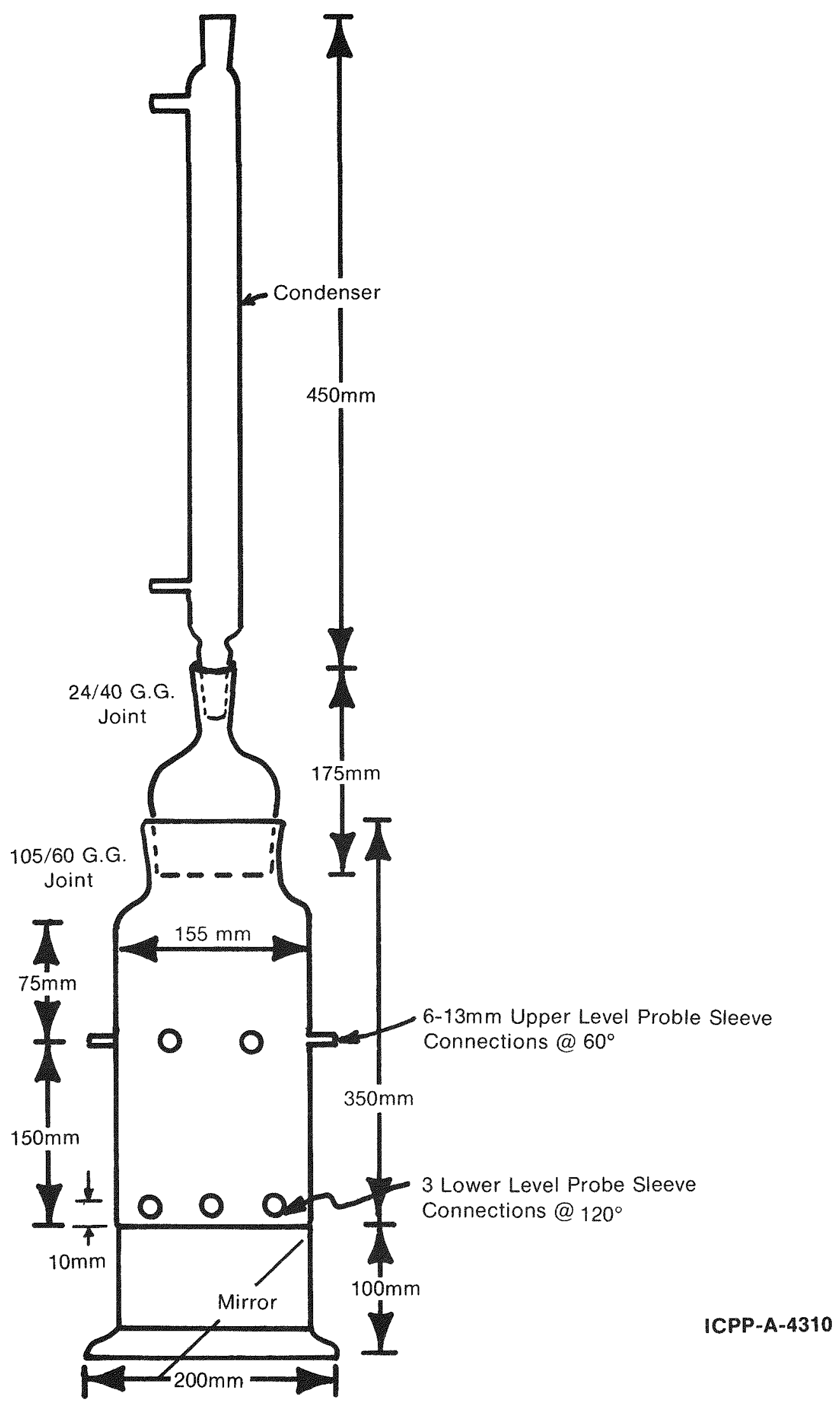

Figure 1. Probe Test Apparatus 


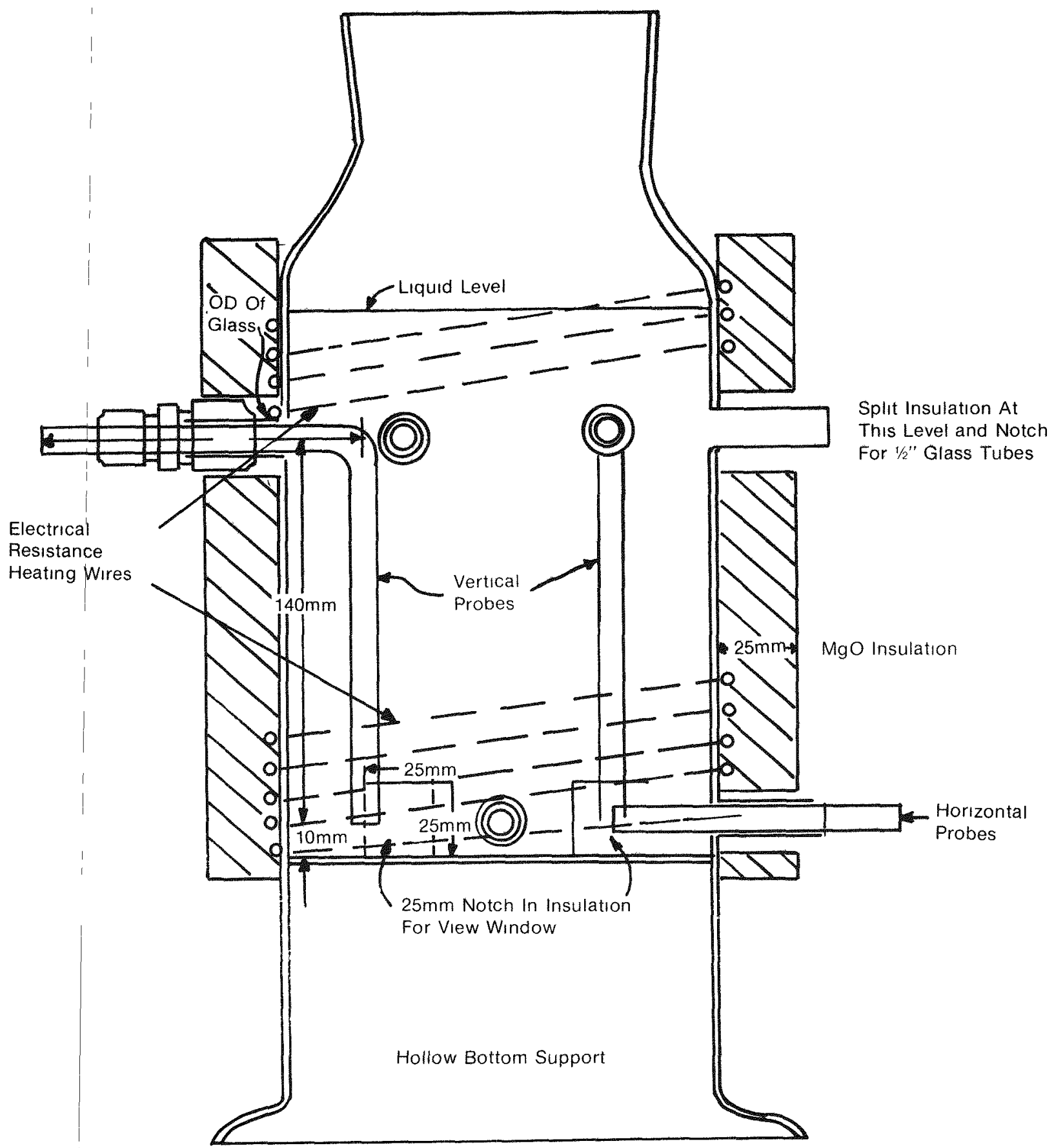

Figure 2. Probe Test Apparatus Details (Including Electrical Resistance Heating Wires and Insulation) 


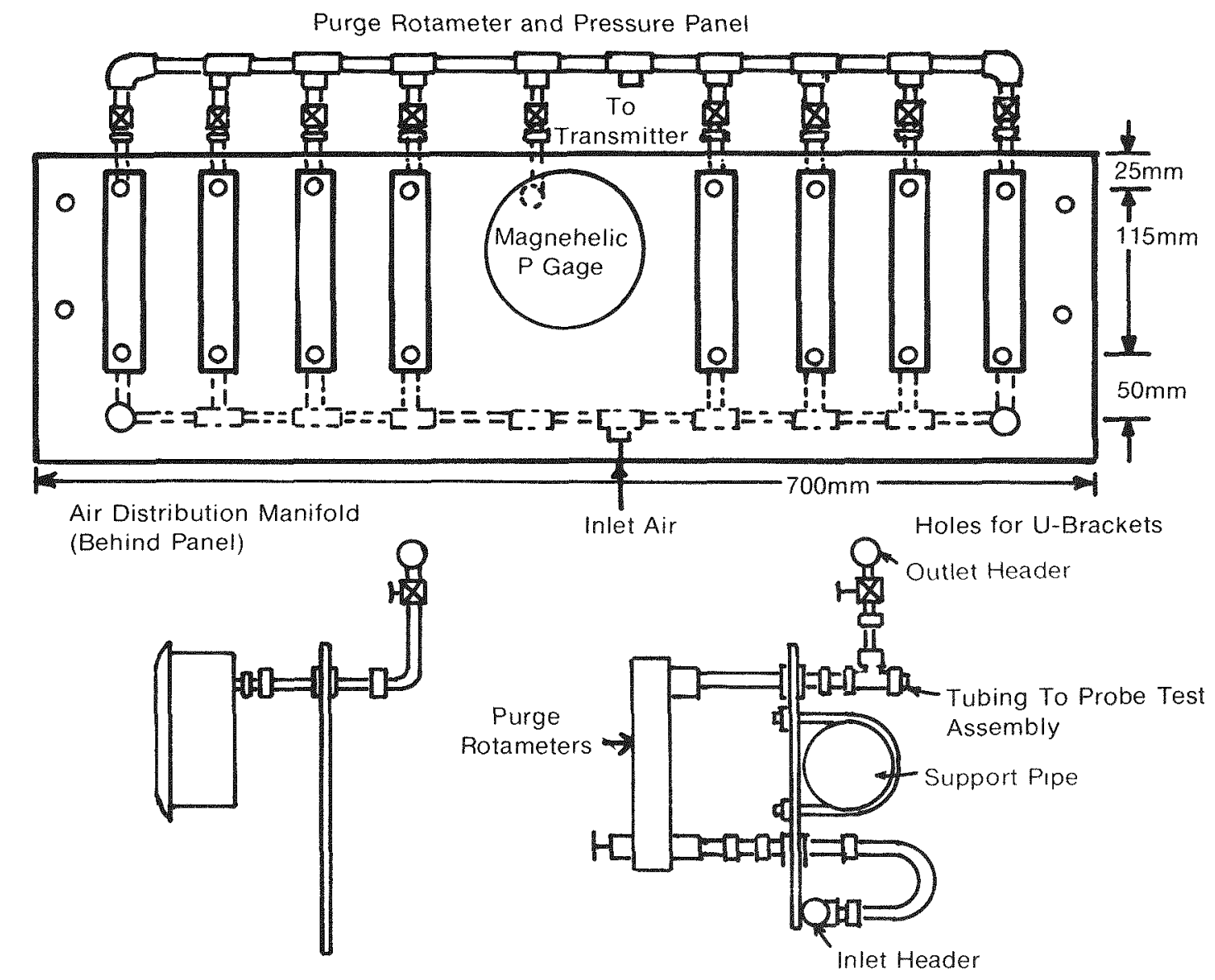

Cross Section at Magnehelic Pressure Gage Location

Cross Section at Rotameter Locations

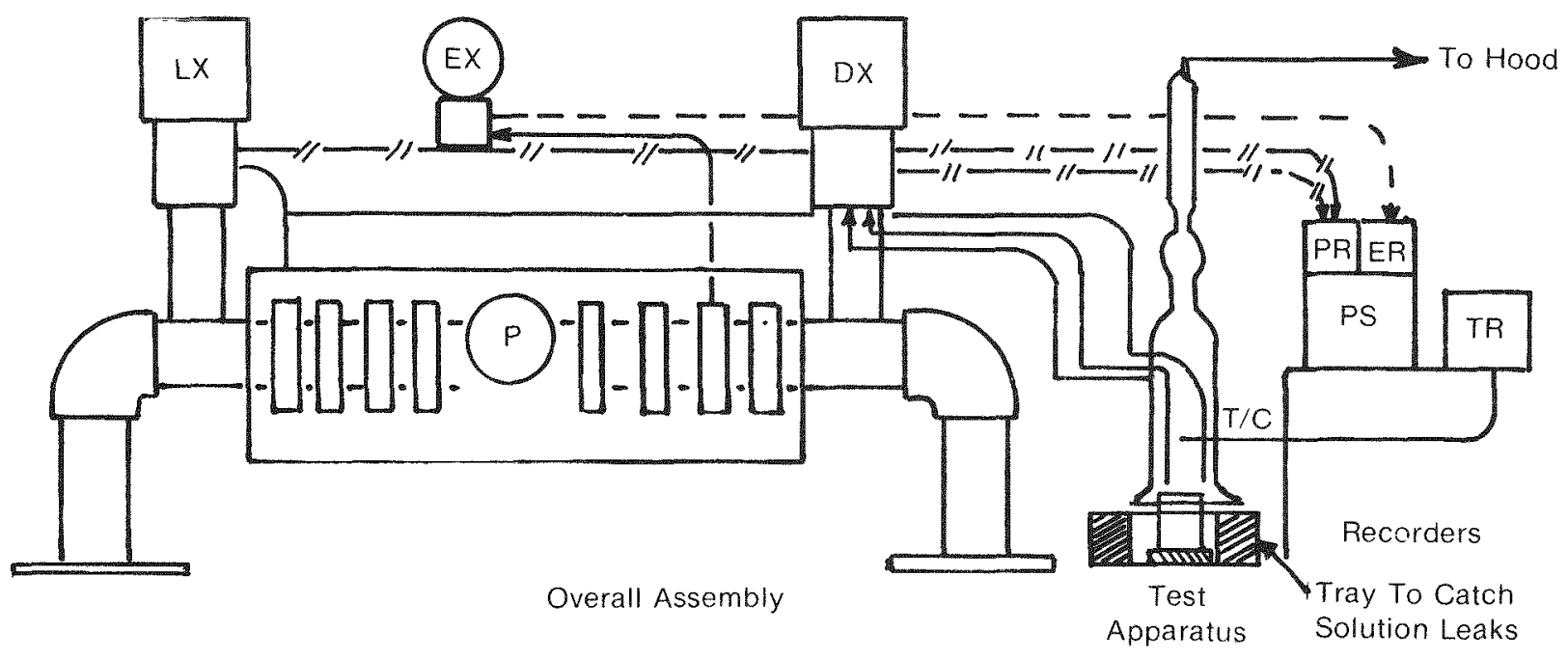

Figure 3. Purge Rotameter Panel and Overall Assembly

ICPP-A-4313 
approximately $25 \mathrm{~cm}$ (10 inches) apart in elevation for simultaneous density measurement. The tube was wrapped with heating tape and insulated for tests at temperatures up to $50^{\circ} \mathrm{C}$.

\subsection{Probes}

Since no one had made a systematic investigation of the effect of probe designs on plugging tendencies, the decision regarding probe designs was made independent of accuracy and precision tests made by other investigators. Figure 4 shows the shapes of the twelve vertical and six horizontal probes tested.

All probes were made of stainless steel, the material of construction for essentially all the probes in the ICPP. The first group of twelve vertical and six horizontal probes was fabricated of 3/8-inch SS tubing for ease of fabrication and for multi-probe installation and testing of the effect of probe shapes. The outside diameter of the horizontal parts of the probes was dressed down to fit through the glass access ports of the test vessel shown in Figure 2 and connectors with nylon ferrules were used to seal the SS tubing probes and the glass access ports. The upper (low pressure) connection to the density transmitter was connected to a horizontal probe in one of the upper access ports and the high pressure tap was connected to a vertical probe in another of the upper access ports. The latter also served as a second Tevel signal.

Although 3/8-inch SS tubing was recommended in most of the 7 iterature reviewed, actual practice at ICPP is to use SS pipe, mostly $1 / 4-i n c h$ Sch 40 or 80 , but $3 / 8,1 / 2$, and $3 / 4$ inch sizes are al so used for better stability and service under corrosive and erosive conditions, Consequentry, after the effect of probe tip design was studied, the selected designs were fabricated of SS pipe in the four pipe sizes to verify optimum size and shape which result in the lowest plugging frequency.

\section{Procedure}

\subsection{Plugging Tests}

The probe test assembly was initially filled with the chosen solution to a depth of 15 to $20 \mathrm{~cm}$. Air was admitted to the probes at $50 \mathrm{smL} / \mathrm{min}(0.1 \mathrm{scfh})$ and the heating elements turned on. After the system temperature stabilized, the purge air was increased to about 500 $\mathrm{smL} / \mathrm{min}$ through each probe to increase the rate of drying, and thereby to shorten the plugging time. Progress of plugging was followed by reading the back pressure recorder output; at first this was done using a manual technique for sampling back pressures of each of the probes. Verification of plugging was ascertained by visual observation through 


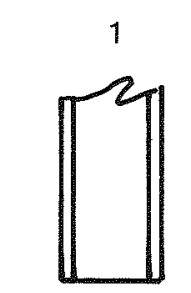

Square Cut

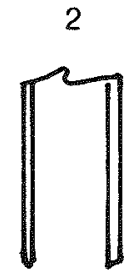

Outside Taper

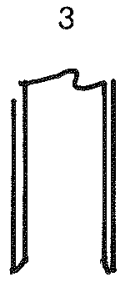

Inside Taper
4

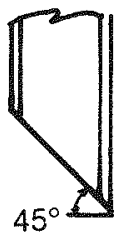

$45^{\circ}$ Bevel
5

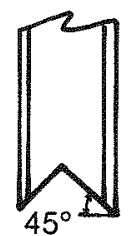

$45^{\circ}$ Notch
6

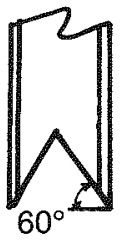

$60^{\circ}$ Notch

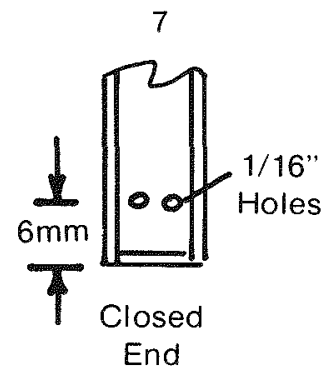

Peripheral

Holes<smiles>[Z]C=CC#CC=C</smiles>

Polyethylene Square
10

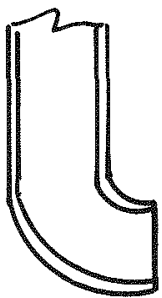

Short $90^{\circ}$
11

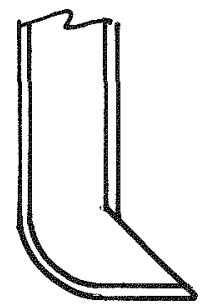

Short Bevel
12

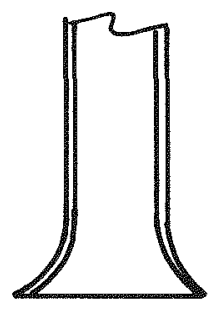

Flare
Orientation "A"

Vertical Probes: numbers as above

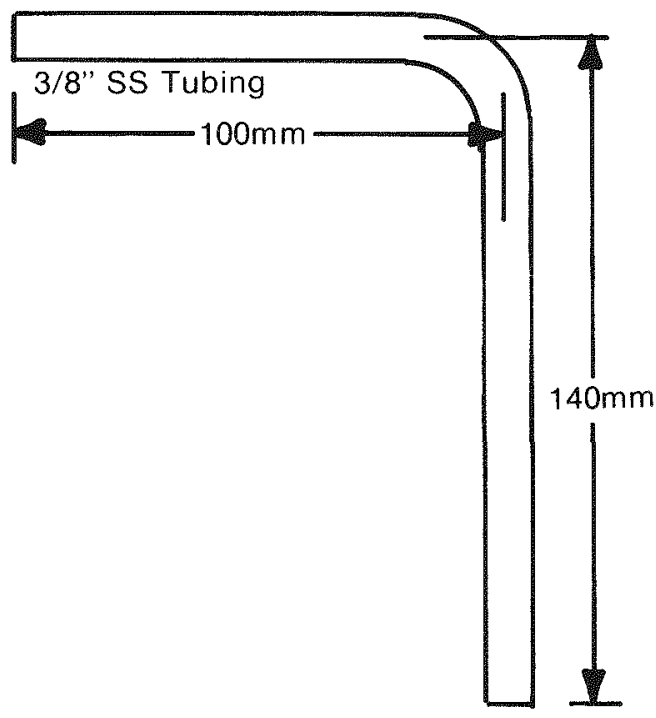

Probe Tip
Orientation " $\mathrm{B}$ "

Horizontal Probes: numbers as below

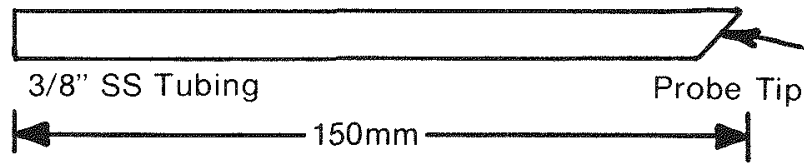

Probe No. 13 Equivalent to No 1 $14 \quad 2$ 154 $16 \quad 6$ $17-7$

18 8

Figure 4. Probe Designs 
the sighting hole in the insulation and by visual observation using the mirror underneath the glass bottom.

Any loss of water vapor from the condenser or appreciable loss of solute by crystallization in the plugs was compensated for by adding water or fresh solution, respectively, at the top of the condenser. Any required solution sample was collected from a tee in the line to one of the bottom probes.

The test solution chosen for the first test was simulated third-cycle raffinate evaporator product solution, consisting of aluminum nitrate (ANN) a solution made by concentrating ANN stock solution to a specific gravity of approximately 1.42 at $25^{\circ} \mathrm{C}$ (equivalent to $2.85 \mathrm{M}$ solution) and adding ammonium hydroxide to provide $0.25 \mathrm{M}$ ammonia. This yielded a solution with a crystallization temperature between 25 and $30^{\circ} \mathrm{C}$.

At the end of each day's run, insulation was reinstalled around the heater element; the power, regulated by a Variac, was turned on to raise the solution temperature overnight and thereby dissolve any crystals formed during the day's test. Testing occurred with the power and insulation off; sometimes a fan was used to accelerate cooling the vessel and its contents.

Purge rates were set at 100,250 , and $500 \mathrm{sml} / \mathrm{min}(0.2,0.4$, and $1.0 \mathrm{scfh})$; normally all probes were operated with a single purge rate for more direct comparisons during a given run. Back pressures in the purge lines could be sampled by opening a purge line valve to a $0-100$ inch water Magnehelic gage. Generally, plugging could be noted by a reduction in rotameter reading and the course of plugging followed with the Magnehelic gage. For those probes connected to level or density recorders, transmitter ranges were low, and beginning of plugging could be detected much earlier than from changes in Magnehelic readings.

Up to three laboratory built humidifiers were inserted into purge lines between the rotameter and test assembly during the first run. They were later replaced by two commercial bubblers, and usually used on one horizontal and the vertical upper probe connected to a density transmitter.

$a_{\text {ANN }}=$ aluminum nitrate nonahydrate. 
A number of the tests were made with probes of different sizes; a few of the early probe size tests were carried out at equal purge rates. The greatest number, however, were made at equal linear velocities from the various-sized probes, generally referenced to a purge rate of $100 \mathrm{smL} / \mathrm{min}(0.2 \mathrm{scfh})$ through a $3 / 8$-inch tubing size probe.

In the effect of liquid depth tests, standard straight cut-off probe tip designs were used for comparative purposes and for shortening the plugging time. Several solution heights from 15 to $105 \mathrm{~cm}$ were used in tests with the third-cycle raffinate (concentrated aluminum nitrate) solution and the concentrated zirconium waste calciner feed solution. Probes were tested at heights from 1 to $25 \mathrm{~cm}$ above the bottom, the latter to get above the final crystal sludge depth in the aluminum nitrate solution. Crystals were dissolved into the solution by heating the insulated plastic tube. Solution cooling was by natural and forced convection. The calcium fluozirconate precipitate was so voluminous in the straight zirconium waste tests that the minimum settleable solids content under static conditions was $70 \%$ of the tested solution depth. In these tests, solid calcium nitrate was added to give a $\mathrm{Ca} / \mathrm{F}$ mole ratio of 0.55 .

\subsection{Unplugging Tests}

Plugs could be removed, if detected early enough, by increasing the air purge rate. If that failed to remove the plug, about $10 \mathrm{~mL}$ of distilled water was added to the probe tubing outside the vessel and forced by purge air to the plug. Sometimes it was necessary, however, to tip the vessel so the water could displace the air in the probe and flow to the plug. Purge air was admitted at a slow rate to allow movement of the water through the plug and to carry the dissolved solute out into the main body of the solution.

A11 plugs encountered during this study were removable by distilled water dissolution or by turning off the air purge and allowing solution to stand in contact with the plug for a short time. Therefore, it was not necessary to use the test apparatus originally planned for pressurized water, acid, or alkali treatment of the plugs. 


\section{RESULTS AND DISCUSSION}

The basic conditions for plugging probes in a batch evaporator were determined originally by actual batch evaporation and concentration in the test apparatus of simulated third-cycle (slightly acid deficient aluminum nitrate) raffinate solution. This concentrated aluminum nitrate solution failed to develop a plug in any of the probes as it was concentrated to more than double its feed concentration as contrasted with on $1 y 30 \%$ concentration in the actual batch evaporator.

Heavy crystallization occurred upon cooling this solution; crystallization and plugging occurred for concentrated product solutions between 20 and $30^{\circ} \mathrm{C}$. Plugging occurred by repeated wetting and drying of the probe surface as the solution entered and was expelled from the probe by the purge gas. Thus, crystallization began and a crystalline plug built up near the end of the probe. Observations showed, however, that crystalline deposits on the glass assembly occurred at the same time that deposits started building on the probes. Usually there appeared to be heavy deposits on the glass assembly by the time the back pressure began building up, signifying that the probe was nearing complete plugging. Plugging of nearly all probes occurred approximately 3 to $6 \mathrm{~mm}$ back from the tip, as illustrated in Figure 5. The plugs essentially filled the probe opening at $25 \mathrm{kPa}$ (100 inches water) back pressure, at which time the probes were removed from the test apparatus for photographing. The opening was approximately $1 \mathrm{~mm}$ when back pressures started increasing and usually the back pressure increased from 1 to $25 \mathrm{kPa}$ (6 to 100 inches water) in one to two minutes.

The concentrated (2.3 $\mathrm{M}$ aluminum nitrate) simulated evaporator product solution was used in the study of all of the following physical variables in items 1 through 5. Probes 10 and 11 had an elbow at the bottom (see Figure 4) and the plugs in these two probes were found at the bend.

\section{Effect of Probe Tip Shape}

Table III presents the data used in determining the best (lowest frequency of plugging) probe shape. Since the probes were tested in three different groups, the best probe of Run 1 was carried over into Run 2, and the best two of Run 2 were carried over to Run 3. This accounts for the three and two sets of readings and calculations for the best probes, which were the polyethylene and SS inverted V-notch tips, respectively. The horizontal, straight cut-off probe was used in two runs in the upper and lower probe tip elevations. Weighted mean values for these three probes were then calculated. Relative ratios of plugging frequencies were then calculated for all probes from which the relative 


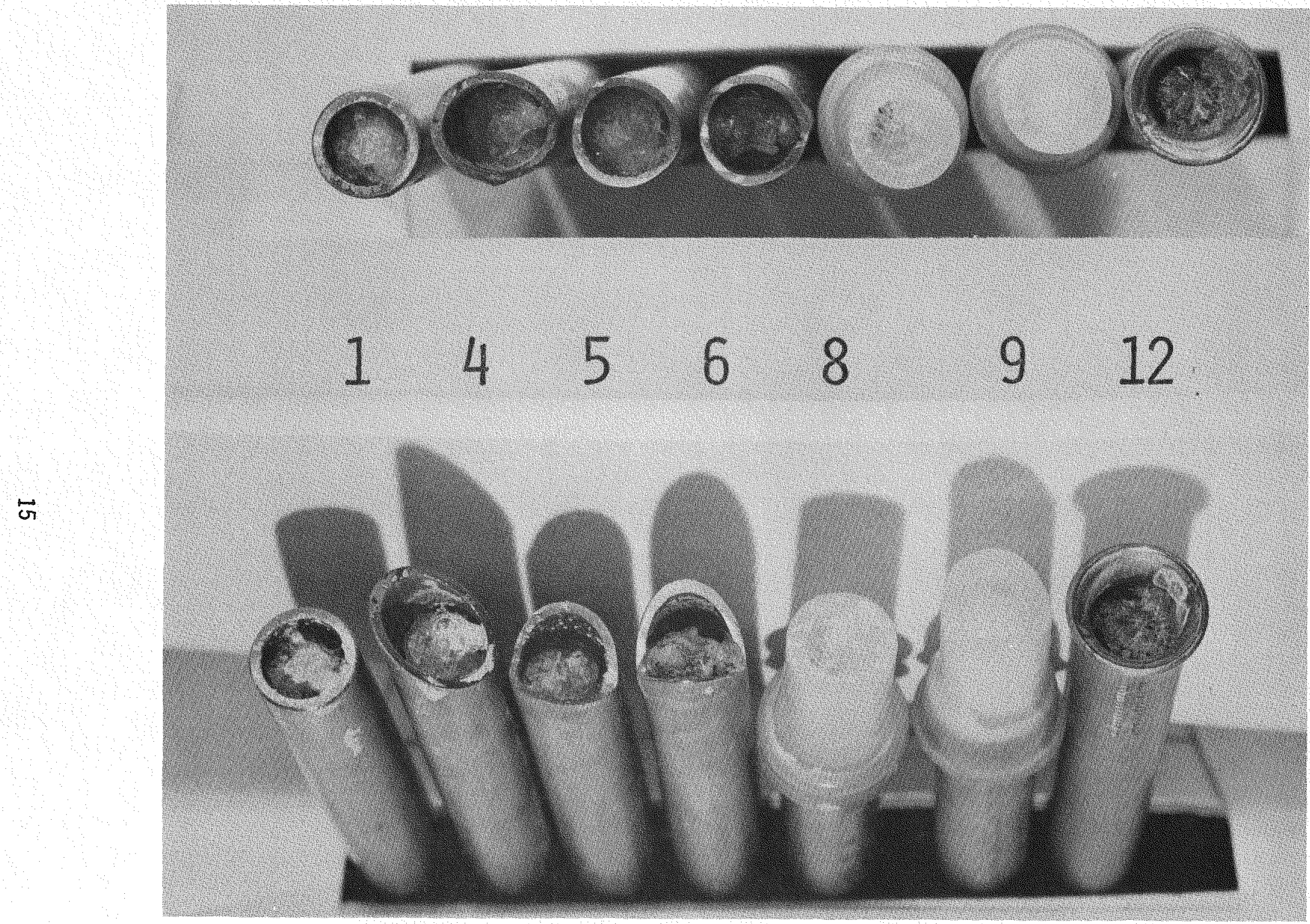

Figure 5. Plugs of Different Probe Tip Shapes (two views) 
TABLE III. PROBE PLUGGING FREQUENCY OF VARIOUS PROBE SHAPES

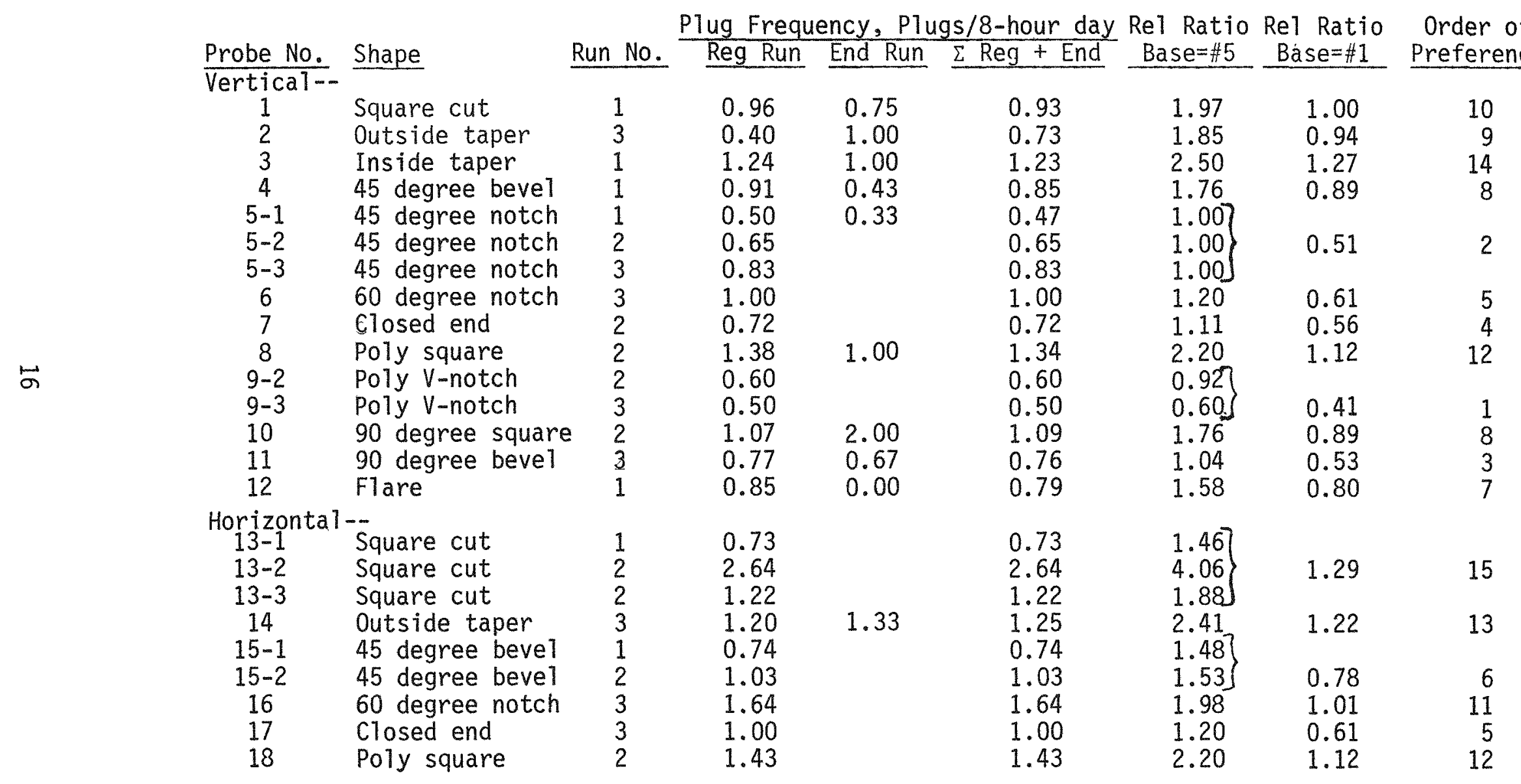


order of preference was determined. This was done for both the regular run and for the regular plus the end run, at which time the commercial bubbler tests were being extended and finally the probes were being deliberately plugged.

The major difference in order of preference was that the outside tapered (\#2) probe appeared the best for the regular run only; however, this value was based upon only 2.5 days running time and only the lowest flow rate. When the final runs were figured in, the \#2 probe still had only 5.5 days run time covering all three purge rates and its order of preference had dropped to fourth place. Other probes had been tested for 10 to 56 days. Thus, the best probe is the polyethylene tipped inverted V-notch design; however, the SS inverted $V$-notch which is almost as good is preferred due to simplicity of fabrication. Their overall plugging frequencies were $57 \%$ and $65 \%$, respectively, of the standard, straight, cut-off design.

\section{Effect of Purge Rate}

The effect of purge rate upon frequency of plugging is presented in Table IV and Figure 6 . At the bottom of the table, the summarized data are segregated into vertical and horizontal probe information. This information is also plotted in Figure 6 . It can be seen that higher purge rates produce higher plugging frequencies: the $250 \mathrm{smL} / \mathrm{min}(0.5$ scfh) purge rate gives $136 \%$ and the $500 \mathrm{smL} / \mathrm{min}$ ( $1 \mathrm{scfh}$ ) purge rate gives $165 \%$ of the plugging frequency encountered with the lower 100 $\mathrm{smL} / \mathrm{min}(0.2 \mathrm{scfh})$ purge rate. These purge rates are equivalent to $3.5,8.5$, and $17 \mathrm{~cm} / \mathrm{sec}(0.1,0.25$, and $6.5 \mathrm{fps}) 7$ inear velocities. It can also be seen that horizontal probes plug $40-50 \%$ more often than vertical ones.

After the trend of decreased plugging rates with decreased purge rates had been established, an extension of the purge rate tests to values as low as $10 \mathrm{smL} / \mathrm{min}(0.02 \mathrm{scfh})$ confirmed that the plugging frequency continued to drop as the purge rate was decreased. Actually, none of these tests showed plugging under normal test conditions at the lowest purge rate of $10 \mathrm{smL} / \mathrm{min}(0.02 \mathrm{scfh}) ;$ a11 probes did plug one night when the ambient temperature dropped abnormally low. It was therefore concluded that increased agitation and drying action with increased purge rates caused the increased plugging frequency at higher purge rates.

\section{Effect of Humidifying the Purge Gas}

The effect of humidification is best noted from the long-term operation of probes 13,16, and 18. During Run 1, humidification resulted in a reduction from 44 plugs in 15 days to no plugs in the next 10 days. 
TABLE IV. EFFECT OF PURGE RATE AND ORIENTATION ON PLUGGING RATES

\begin{tabular}{|c|c|c|}
\hline Orientation & $\begin{array}{l}\text { Probe } \\
\text { No. }\end{array}$ & Shape \\
\hline Vertical & $\begin{array}{c}1 \\
2 \\
3 \\
4 \\
5-1 \\
5-2 \\
5-3 \\
6 \\
7 \\
8 \\
9-2 \\
9-3 \\
10 \\
11 \\
12 \\
1 \\
1 \\
1\end{array}$ & $\begin{array}{l}\text { Square cut } \\
\text { Outside taper } \\
\text { Inside taper } \\
45^{\circ} \text { bevel } \\
45^{\circ} \text { notch } \\
45^{\circ} \text { notch } \\
45^{\circ} \text { notch } \\
60^{\circ} \text { notch } \\
\text { Closed end } \\
\text { Poly square } \\
\text { Poly V-notch } \\
\text { Poly V-notch } \\
90^{\circ} \text { square } \\
90^{\circ} \text { bevel } \\
\text { Flare }\end{array}$ \\
\hline
\end{tabular}

Run Purge Rate, sccm

No. $15 \quad 50 \quad 100 \quad 250 \quad 500$ Mean $\Sigma$ Re1. Ratio

$\begin{array}{ccll}\text { Horizonta] } & 13-1 & \text { Square cut } & 1 \\ & 13-2 & \text { Square cut } & 2 \\ 13-3 & \text { Square cut } & 2 \\ 14 & \text { Outside taper } & 3 \\ 15-1 & 450 \text { bevel } & 1 \\ 15-2 & 45^{\circ} \text { bevel } & 2 \\ 16 & 60^{\circ} \text { notch } & 3 \\ 17 & \text { closed end } & 3 \\ 18 & \text { Poly square } & 2\end{array}$

$\begin{array}{lll}\text { Totals } & \text { Vertical } & \begin{array}{l}\text { Plugs } \\ \text { Days }\end{array} \\ \text { Mean } & & \text { Freq. } \\ \text { Totals } & \text { Horizontal } & \begin{array}{l}\text { Plugs } \\ \text { Days }\end{array} \\ \text { Mean } & & \text { Freq. }\end{array}$

Grand Mean

Relative Ratio

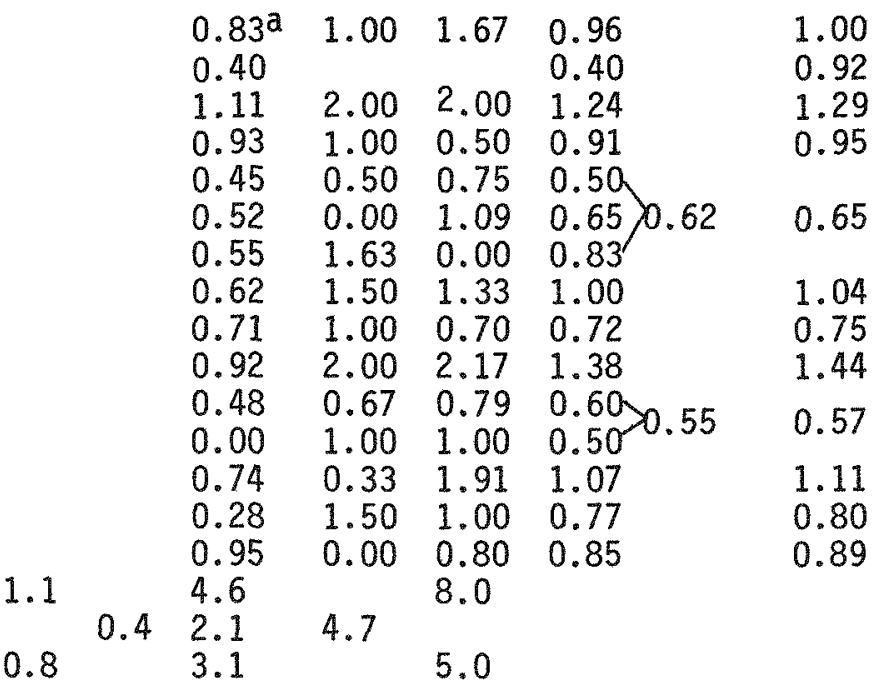

\begin{tabular}{|c|c|c|c|c|}
\hline $\begin{array}{l}0.67 \\
2.67 \\
0.67 \\
1.2\end{array}$ & $\begin{array}{l}1.00 \\
2.50 \\
1.33\end{array}$ & $\begin{array}{l}1.00 \\
2.60 \\
2.13\end{array}$ & $\begin{array}{l}0.73 \\
2.64>1.57 \\
1.22 \\
1.20\end{array}$ & 1.64 \\
\hline & $\begin{array}{l}1.00 \\
2.00\end{array}$ & $\begin{array}{l}1.50 \\
1.07\end{array}$ & $\begin{array}{l}0.74 \\
1.03\end{array} 0.97$ & 0.91 \\
\hline $\begin{array}{l}1.43 \\
0.77 \\
0.00\end{array}$ & $\begin{array}{l}2.00 \\
0.86 \\
1.00\end{array}$ & $\begin{array}{l}2.00 \\
3.00 \\
2.67\end{array}$ & $\begin{array}{l}1.64 \\
1.00 \\
1.43\end{array}$ & $\begin{array}{l}1.71 \\
1.04 \\
1.49\end{array}$ \\
\hline
\end{tabular}

$\begin{array}{llll}136 & 35 & 67 & 239\end{array}$

$185 \quad 33 \quad 55.75269$

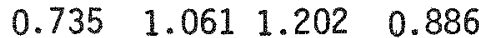

$\begin{array}{llll}98 & 20 & 47.5 & 165.5\end{array}$

$\begin{array}{llll}89 & 14.5 & 25.5 & 129\end{array}$

$\begin{array}{llll}1.101 & 1.379 & 1.863 & 1.283\end{array}$

$0.854 \quad 1.158 \quad 1.409 \quad 1.004$

$\begin{array}{llll}1.00 & 1.356 & 1.650 & 1.006\end{array}$

aplugging frequency in plugs/8-hour day. 


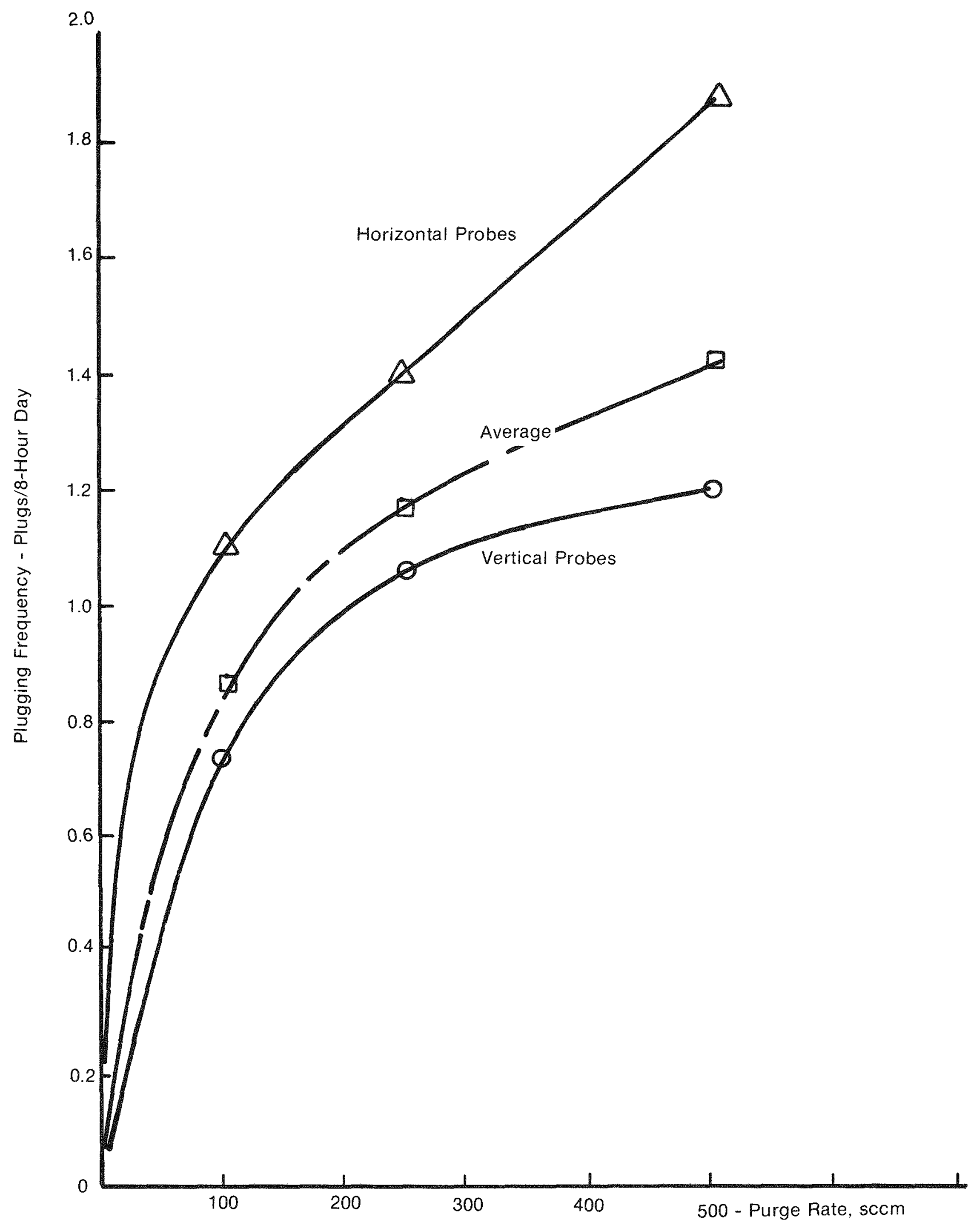

Figure 6. Effect of Purge Rate Upon Plugging Frequency 
Run 2 disclosed five plugs in four days before inserting the humidifier, followed by 14 days of no plugging when humidified air was used.

During Run 3 , there were 11 plugs in seven days before installing the humidifier, and no plugs in eight days after its installation. At the end of Run 3, the humidifiers were removed and the purge rate increased to $500 \mathrm{smL} / \mathrm{min}$ (1 scfh), resulting in plugging of all probes within an hour. Commercial Meriam Model 93155 bubblers produced relative humidities of $50-80 \%$ at purge rates of $100-500 \mathrm{smL} / \mathrm{min}(0.2-1 \mathrm{scfh})$, respectively; they were installed early in Run 3 and proved entirely satisfactory operating at room temperatures. A reduction in plugging rate of one to two orders of magnitude is indicated for humidified purge gas. Sma11 water washes were adequate to dissolve any of the plugs encountered in these tests.

\section{Effect of Probe Size}

The effect of probe size from 3/8-inch tubing to 3/4-inch pipe was determined in the same acid-deficient aluminum nitrate solution used in the previous tests, for both standard straight cut-off and inverted $V$-notch probe tip shapes. These were tested under three equal flow and three equal linear velocity conditions. The probe plug conditions at the end of one of the runs are shown in Figure 7 . All plugging times were normalized to the time of first crystallization, since the starting temperatures varied. The results are shown in Figure 8 . The plugging time increases with an increase in probe size, since larger amounts of deposits are required to fill the probe cross section.

\section{Effect of Liquid Depth}

Tests on the effect of solution depth on plugging time indicated that no significant relationship existed. Both third-cycle raffinate and concentrated zirconium waste calciner feed (including calcium nitrate addition) were tested. Crystallization of aluminum nitrate occurred with the raffinate solution as in the multi-probe test apparatus. With the probes located near the bottom of the vesse1, greater amounts of sludge crystals were formed at the bottom and this appeared to prolong the time of probe operation over that when the probes were located above the sludge bed. This may be due to scouring action of the sludge or to greater desaturation of the solution, especially at the probe location. There was essentially no settling of the zirconium fluozirconate precipitate in the calciner feed solution; it had a free settling volume of about $70 \%$ sludge, as long as air purge was maintained through the probes. When the air was shut off from one of the probes, however, the temperature of the heated solution rose and some settling occured, causing the unpurged probe to plug very tightiy; $140 \mathrm{kPa}$ (20 psi) air would not remove the plug. 


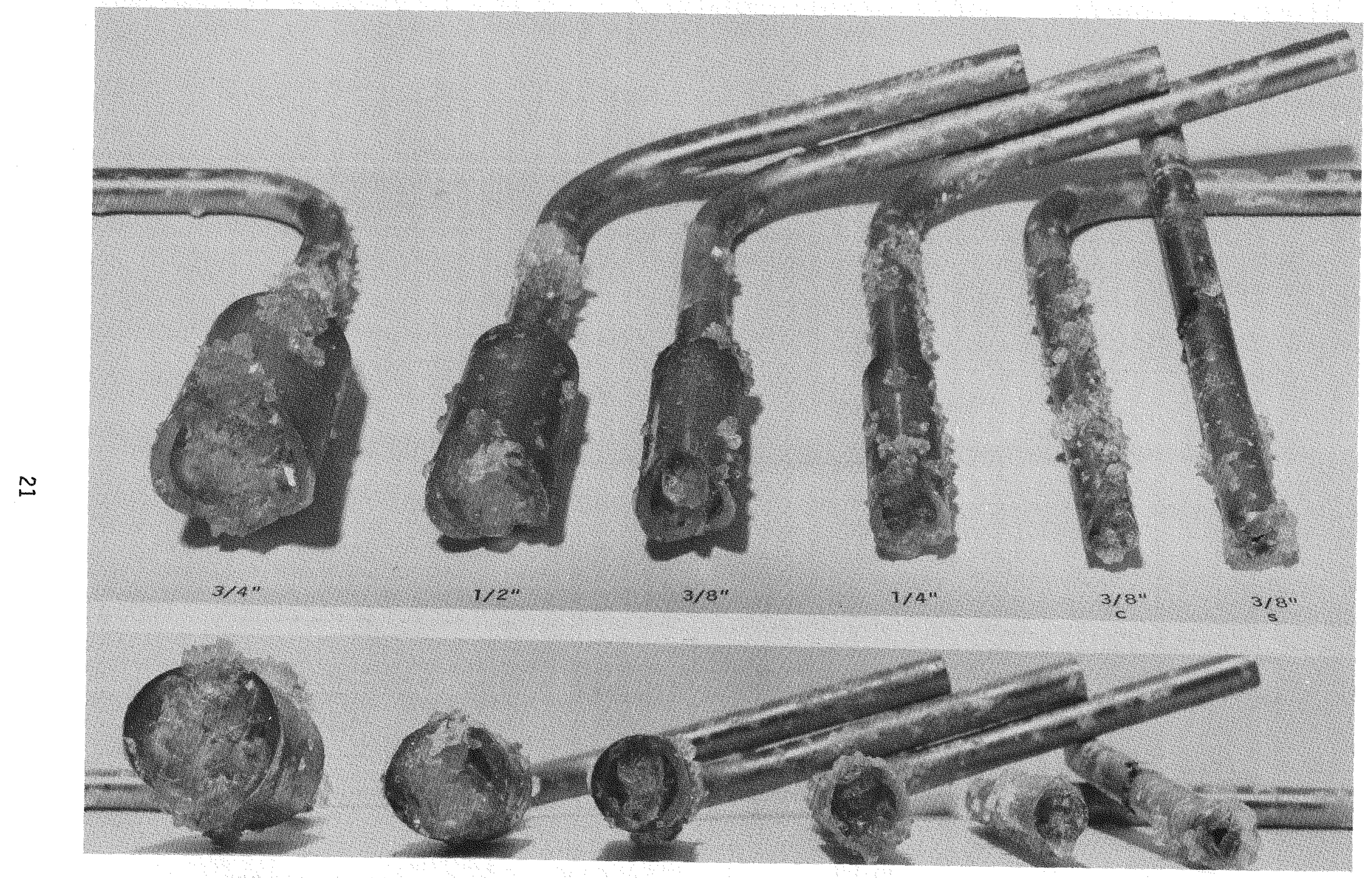

Figure 7. Plugs of Different Size Probes (two views) 


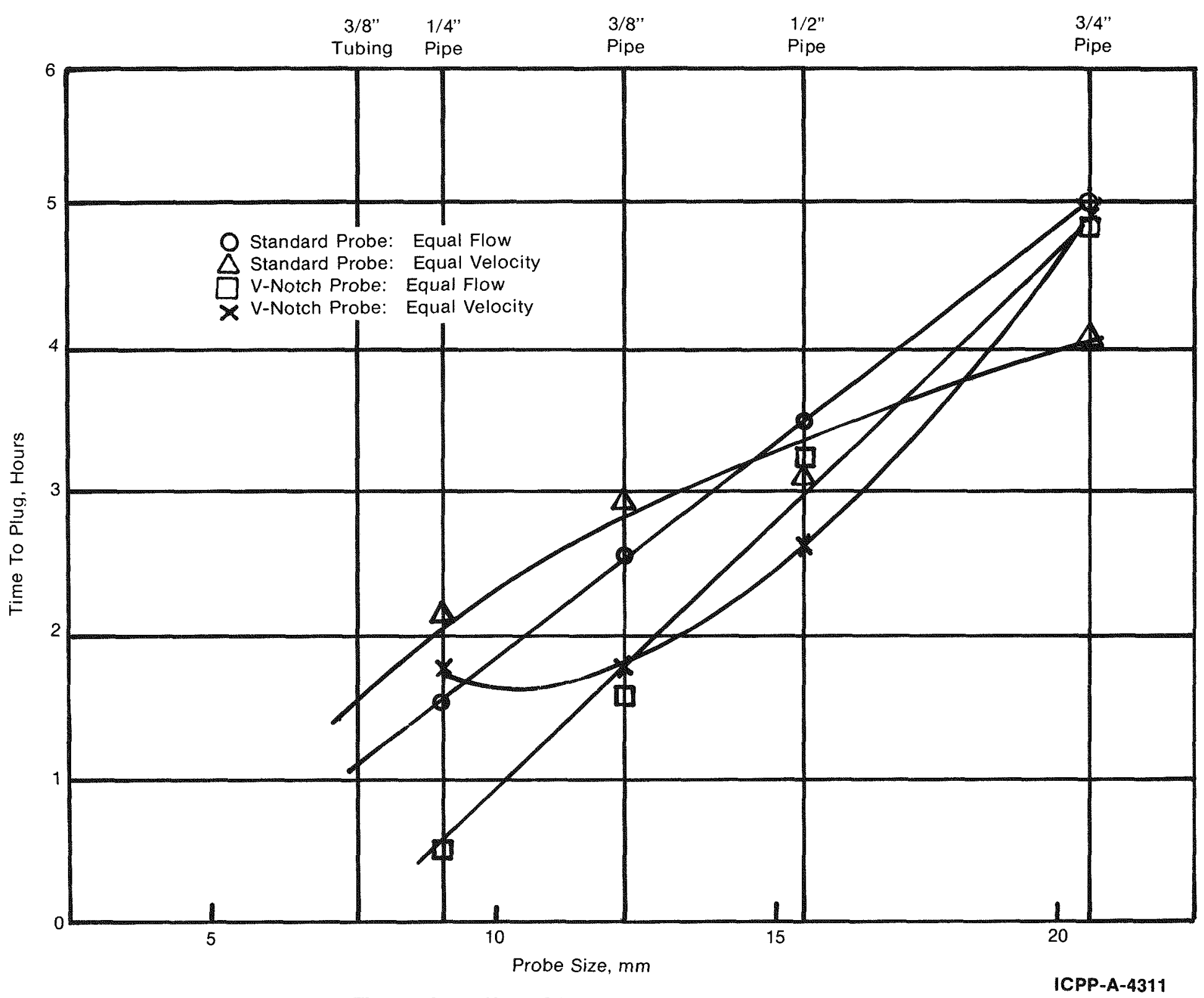

Figure 8. Effect Of Probe Size On Plugging Time 


\section{Effect of Types of Solution}

\subsection{Acid Deficient Aluminum Nitrate Batch Evaporator Product}

The acid deficient aluminum nitrate solution simulating that concentrated in the third-cycle raffinate evaporator was used in the study of all the above basic variables. Its behavior was discussed in detail in the preceeding results.

\subsection{Low Fluoride Sodium-Zirconium Blend Waste Calciner Feed}

The first calciner feed solution tested was a simulated $5: 1$ zirconium:sodium waste blend to which calcium nitrate was added as a solid to give a $\mathrm{Ca} / \mathrm{F}$ mole ratio of 0.7 . The zirconium waste was low $(1.16 \mathrm{M})$ in fluoride, equivalent to the dilute wastes in WM-182, 188 , and 189 waste storage tanks. This solution had very little CaZrF 6 precipitate. None of the five probes tested in the solution plugged or even built up a visible deposit during a nine-day testing period, two days at ambient temperatures and seven days at $50^{\circ} \mathrm{C}$.

\subsection{High Fluoride Concentrated Zirconium Waste Calciner Feed}

The second calciner feed solution tested was a concentrated zirconium fluoride mixture $(3.67 \mathrm{M} \mathrm{F-)}$ similar to the WM-185 composition, to which calcium nitrate was added as a solid to provide a Ca/F mole ratio of 0.55 . This resulted in a very thick suspension with $71 \%$ by volume settleable solids. Two standard probes of $3 / 8$-inch tubing and 1/4-inch pipe were immersed to $12.5 \mathrm{~mm}$ above the bottom in $150 \mathrm{~mm}$ first, then $350 \mathrm{~mm}$, then $1000 \mathrm{~mm}$ depth in a $57-\mathrm{mm}$ diameter $\times 1000 \mathrm{~mm}$ tal1 plastic tube for one day, one week, and two weeks operating time, respectively; no plugging occured at any of the above depths or operating times.

At the end of the second interval, the two probes appeared to have closed down to approximately $2 \mathrm{~mm}$ diameter air opening but with no increase in back pressure. During the final two weeks testing, the temperature was raised from ambient to $55^{\circ} \mathrm{C}$. No plugging developed in the standard $3 / 8$-inch tubing probe which had continuous purging. At the end of the testing period, the purge air was shut off from the 1/4-inch standard tubing probe, resulting in an increase in temperature of the heated column to $760 \mathrm{C}$, a settling of the solids to about $35 \%$ of the solution level, and a plug in the non-purged probe. The purged probe remained clear. The plug could not be broken with $140 \mathrm{kPa}(20 \mathrm{psig})$ instrument air pressure. 
The same suspension was tested in the multi-probe test apparatus for eight days at $50^{\circ} \mathrm{C}$ with no significant plugging tendency, al though two probes had a slight increase in back pressure. A procedure was used for two weeks to simulate draining and refilling of calciner feed tanks; after draining the vessel daily, continued air purging was allowed for approximately two hours before the vessel was refilled with solution. No plugs developed, but it was observed that the sludge depth directly under the probes was only a fraction as high as between the probes. If the purge air failed in the plant, the probe tip could be below the sludge level, especially if the sludge was not resuspended or removed between batches. This condition and the final condition of the probes are shown in Figure 9.

\subsection{Borated Cooling Water}

Borated cooling water is used as a nuclear poison in the zirconium fuels dissolver. This solution is normally $6 \mathrm{gB} / \mathrm{L}$ strength, has a maximum temperature of about $65^{\circ} \mathrm{C}$, and a minimum of ambient temperature. Inspection of the probes after three weeks operation at $50-65^{\circ} \mathrm{C}$ showed plugging of about half of the cross sectional areas, but no increase in back-pressure, which is the actual measured variable, at constant level conditions. During about half of this time, two probes operated with a 6-minute cycle of purge air on and off. The probes were then operated for two days at ambient temperature, with no additional apparent plugging.

The boron concentration was then increased to $8 \mathrm{gB} / \mathrm{L}$ and the test continued at ambient temperatures after initial addition of the extra boric acid. Deposits formed on the bottom of the apparatus and in the probes, sometimes causing sufficient back pressure (about $100 \mathrm{kPa}$ or 15 psig) to blow the plastic tubing off several probes. At the end of two weeks' operation using the $8 \mathrm{gB} / \mathrm{L}$ at ambient temperatures, al1 vertical probes were nearly plugged and exhibited some increases in measured back pressures. Figure 10 shows the probe condition at the end of both tests. The horizontal probes did not plug, presumably because there appeared to be solution in those probes; water washing or soaking of the probes was sufficient to dissolve the plugs enough to restore normal level readings.

\subsection{Process Equipment Waste (PEW)}

A simulated PEW waste solution was prepared, based upon the WM-186 tank composition less $\mathrm{Zr}, \mathrm{Al}, \mathrm{F}$, and associated nitrate. Calcium, magnesium, and silica equivalent to a 20 fold concentration of them from raw water were added, since they were not covered in the WM-186 analysis. The probes were inspected after a weekend test at $80^{\circ} \mathrm{C}\left(175^{\circ} \mathrm{F}\right)$ 

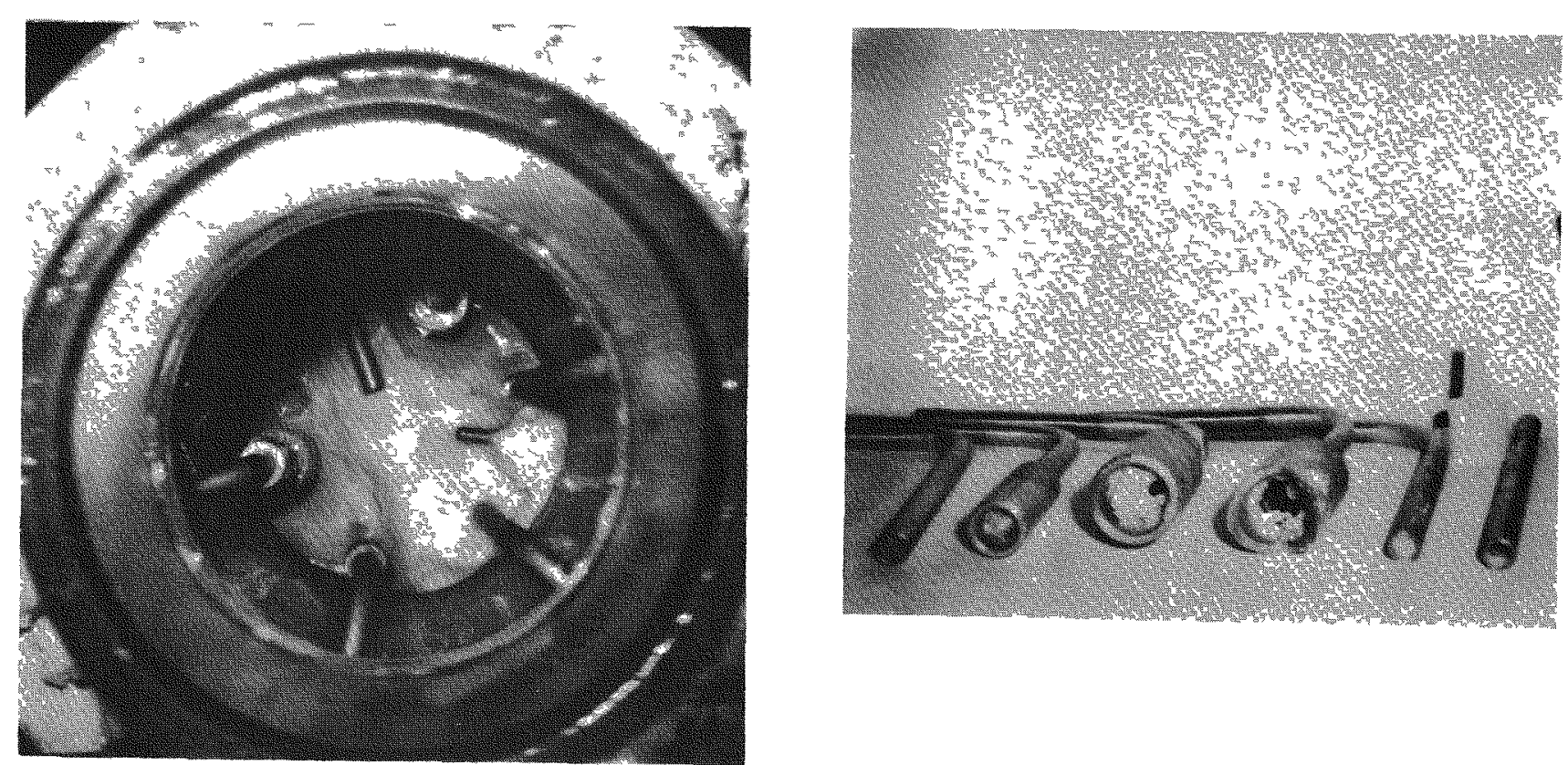

Figure 9. High Fluoride Zirconium Waste Calciner Feed Test a. Sludge Pattern after Draining Vessel

b. Partial Probe Plugs after Draining Vessel 

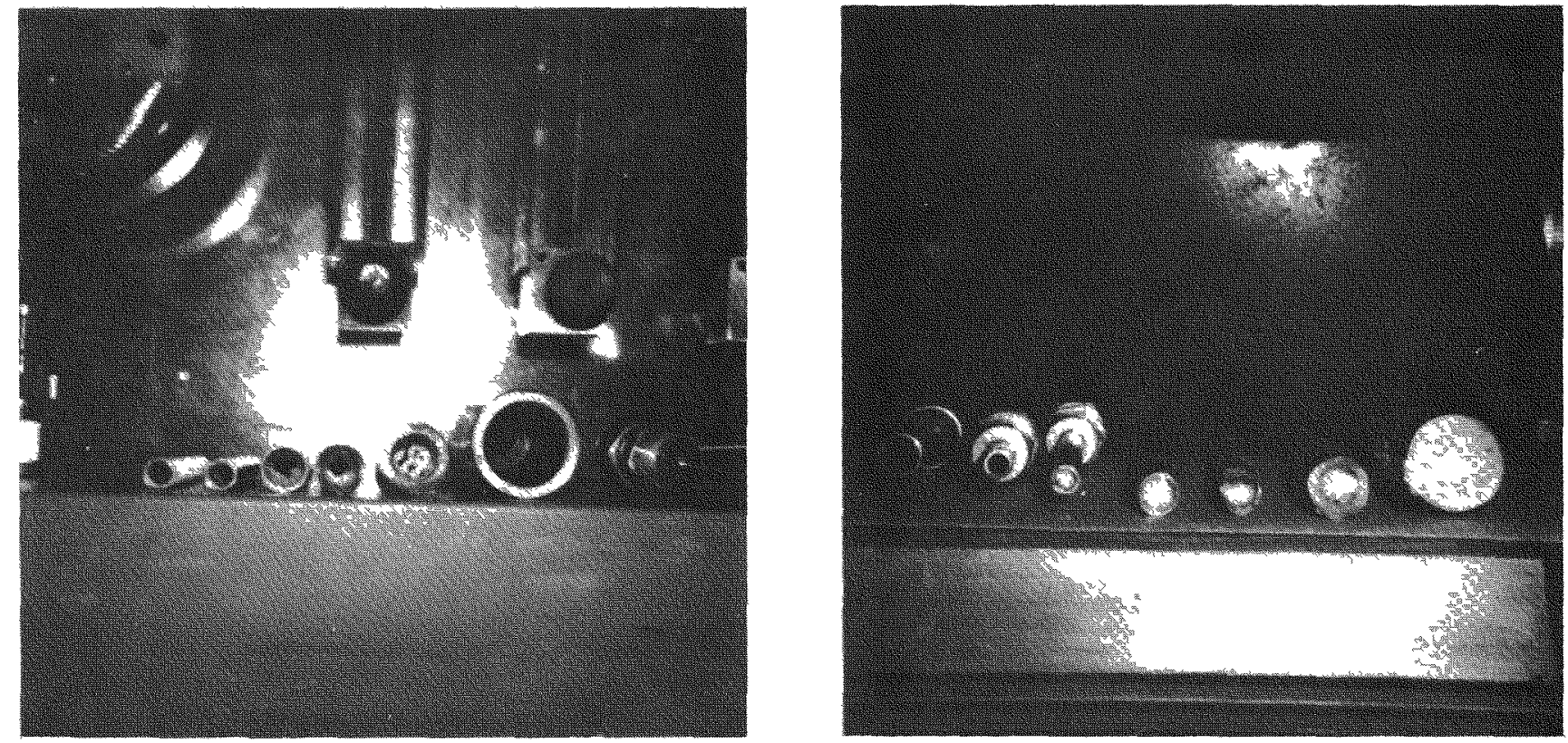

Figure 10. Borated Cooling Water Test

a. Effect of Probe Size on Plugging with $6 \mathrm{gB} / \mathrm{L}$

b. Effect of Probe Size on Plugging with $8 \mathrm{gB} / \mathrm{L}$ 
and also after draining the hot $\left(96^{\circ} \mathrm{C}\right)$ contents two days later; both showed considerable deposits but not enough to increase back pressure readings. In terms of percent of area plugged, the larger probes appeared to be plugged more than the smaller ones.

A failure in the cooling water supply allowed a ten-fold concentration of this solution, which plugged all probes almost completely, as shown in Figure 11. Dissolution of the plugs occured most readily in the larger probes. A 20-mm diameter ring of hard black scale developed at the original liquid level on the side of the apparatus, as shown in Figure 12. X-ray diffraction analyses showed this to be $\mathrm{KMn}_{8} \mathrm{O}_{16}$ and aluminum sulfate hydrate; although no aluminum had been added in the preparation of the simulated PEW solution, it was also found as a minor constituent by the emission spectrograph. The principal constituent of this scale, the lower scale, and the bottom sludge was sodium nitrate, which was expected from the original composition of the solution. Some $\mathrm{CaSO}_{4}$ was found; silica was found by the emission spectrograph.

\subsection{Complexed Fluorinel Dissolver Product}

A radioactively cold simulated Fluorinel complexed dissolver product solution was the final solution tested. This solution did not have any uranium in it for the first week's testing during which time no complete plugs developed at a temperature of $50 \mathrm{C}$. One and a half grams $U$ per $L$ were then added and the test continued up to a temperature of $80^{\circ} \mathrm{C}$. Partial plugging was determined visually, but there was no increase in back pressure readings, except temporarily for one probe. A slow decrease in back pressure on three recorder traces was found due to evaporation and/or slow leakage of the solution over a month's period. As with the malfunction at the end of the PEW test, a 20-mm diameter half-ring of scale was found at the center line of the upper probes, which was the original liquid level. Scale was also deposited on the sides and bottom of the vessel. The ring scale was only slightly soluble in boiling distilled water but was attacked considerably by boiling 6 M nitric acid.

\section{Unplugging Studies}

Essentially all plugs from the simulated solutions used were readily dissolvable in water. If plugging was detected early, as by noticing a marked trend of increasing readings, an increase of five to ten-fold in purge rate was often sufficient to break the plug. If that failed, addition of $10 \mathrm{~mL}$ of distilled water to these short 3/8-inch tubing probes dissolved the plugs. After the addition of the water, purge air was admitted at a normal or lower rate to force the water through 

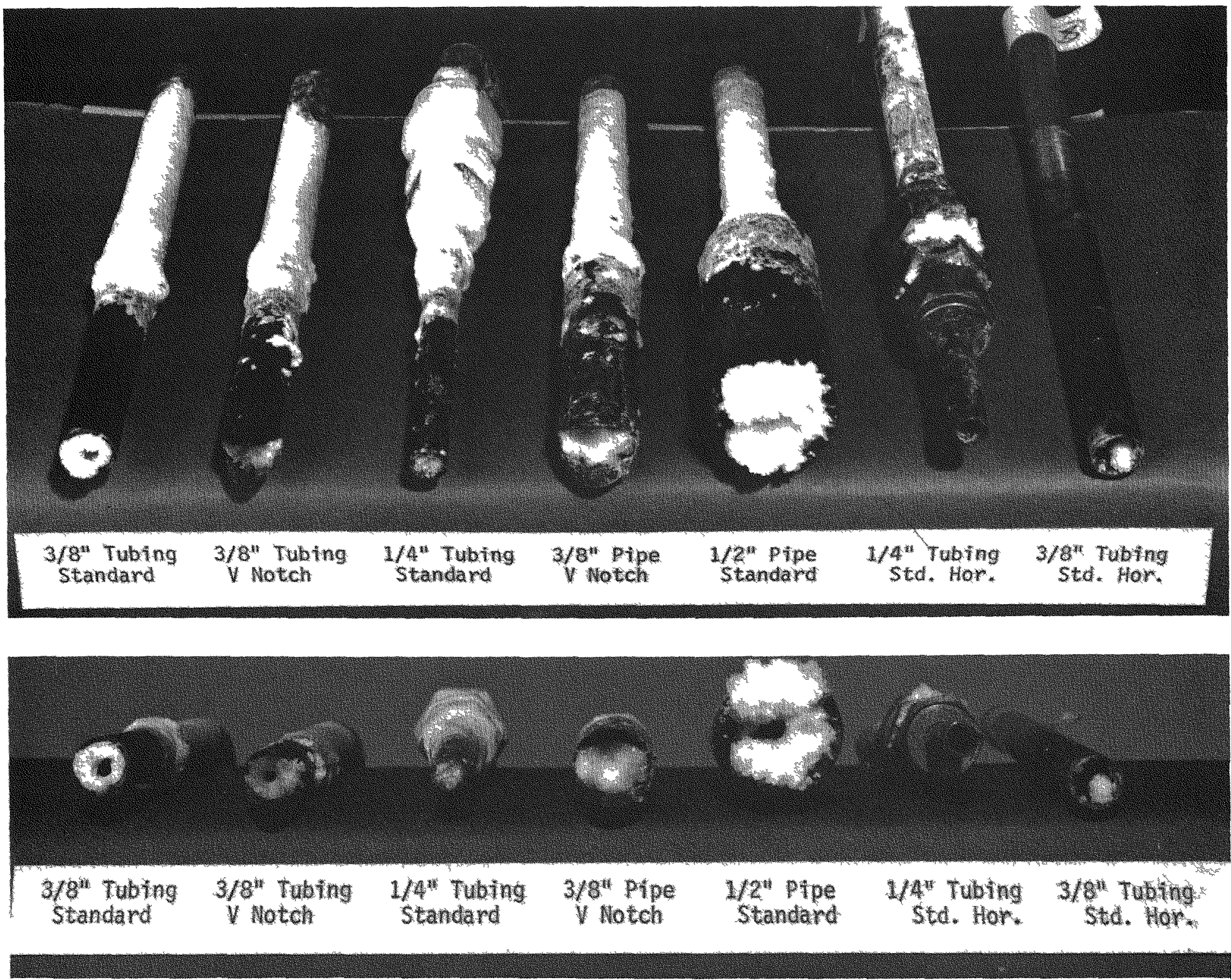

Figure 11. Effect of Probe Size on Plugging with Concentrated PEW Solution 

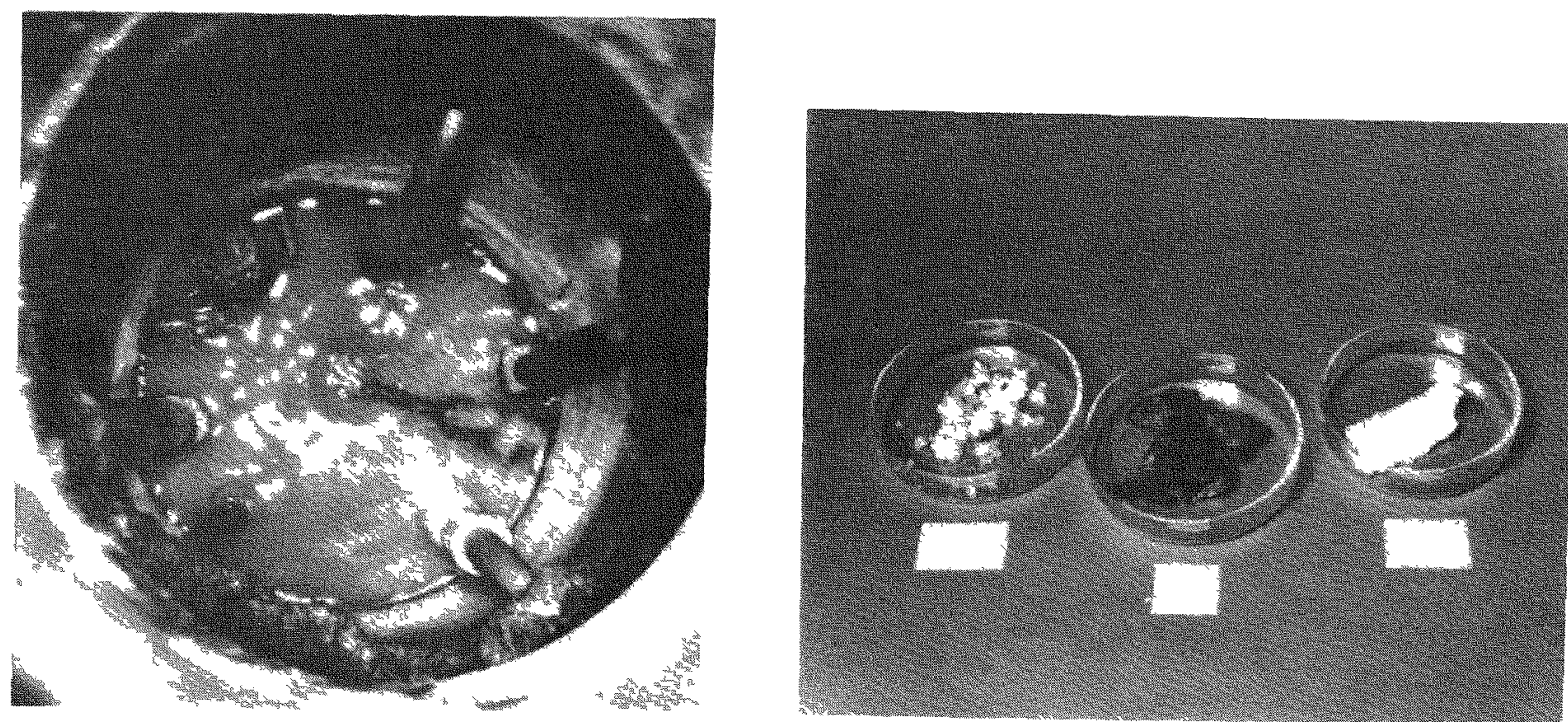

Figure 12. PEW Test After 85\% Boildown

a. Plan View of Scales in Vessel

b. Scale and Sludge Samples 
any cracks in the plug and to carry it out into the solution. STower purge rate during this operation allowed more solute to dissolve in the water.

Turning off the purge air and allowing the probes to soak in the solution was also useful when the solution was not saturated. For crystallizing type solutions, plugs can also be removed by heating the solution above the crystallizing temperature. Larger probes appear to be easier to free of plugs. While boiling nitric acid was effective in attacking the Fluorinel scale, alkaline Turco was better than water or nitric acid in dissolving the scale from the PEW test, probably because of the silica in the PEW scale.

\section{Probe Orientation}

For aluminum nitrate bearing solutions, horizontal probes have a higher frequency of plugging than vertically oriented probes. The same conclusion was not definite for other type solutions.

\section{Plugging Indications}

Probes will be nearly completely plugged by the time level or density readings begin to show a significant increase; this is because the opening through the plug for purge air to escape is only about 1-mm in diameter when the increase begins. Plugging is usually indicated by a rapid increase in reading, often going off-scale within two minutes. 


\section{CONCLUSIONS}

Based on the results of this study, plugging can generally be considered to be due to crystallization or deposition of material from solution by alternate wetting and drying of the probe tips. The following specific conclusions were based on the tests:

1. For crystallizing type solutions, plugging can be eliminated or reduced if the solution temperature is kept above the crystallization temperature. Also, plugs can be dissolved by heating the solution above the crystallization temperature. It requires from one to four hours to break the plugs in this manner.

2. The greatest potential improvement in reducing plugging can be achieved by humidifying the purge gas. This is especially attractive if the solution temperature is not above $40-50^{\circ} \mathrm{C}$; higher temperatures would require operating the humidifiers at similar temperatures and providing a means for continual or frequent addition of water to the humidifiers. Relative humidities of $50-80 \%$ are easily obtained from a commercial Meriam Model 93155 bubbler operating at room temperature with purge rates of 100 to $500 \mathrm{smL} / \mathrm{min}(0.2-1 \mathrm{scfh})$, respectively. Any humidification of the purge gas streams should reduce plugging frequencies by at least an order of magnitude and may eliminate the problem entirely.

3. Plugging rates increase with an increase in purge rate, apparently due to the relative amount of drying action. Within the usual purge rates of $100-500 \mathrm{smL} / \mathrm{min}(0.2-1 \mathrm{scfh})$, the $100 \mathrm{smL} / \mathrm{min}$ purge rate resulted in $73 \%$ of the plugging frequency for the $250 \mathrm{smL} / \mathrm{min}$ rate and $60 \%$ of the plugging frequency of the $500 \mathrm{smL} / \mathrm{min}$ purge rate, using $3 / 8$-inch tubing size probes. These are equivalent to linear velocities of $3.5,8.5$, and $17 \mathrm{~cm} / \mathrm{sec}(0.1,0.25$, and $0.5 \mathrm{ft} / \mathrm{sec})$ for the 100,250 , and $500 \mathrm{smL} / \mathrm{min}$ rates. Very low purge rates of $10 \mathrm{smL} / \mathrm{min}(0.02 \mathrm{scfh})$ show further improvement, with a plugging frequency of on $1 \mathrm{y} 10 \%$ of that of $500 \mathrm{smL} / \mathrm{min}$, but will require very low flow purge meters, which are not readily available from manufacturers. It is concluded that the lowest purge rate - 20 to $100 \mathrm{smL} / \mathrm{min}$ depending on probe size -- that will assure a few (10) bubbles per minute of purge gas to flow from the probe will produce the fewest plugs.

4. Plugging rates decrease with an increase in probe size, largely due to the greater area that must become plugged. A two to four-fold improvement in reduced plugging is indicated for 3/4-inch pipe size compared to 1/4-inch pipe size. The structure of the plug appeared weaker and more susceptible to breaking or dissolving in the larger probes. Since the plugs for all size probes appear to be about $1 \mathrm{~cm}$ 
inside the tip of the probe, only the last 5 to $10 \mathrm{~cm}$ of the probe need to be of the larger size, with the rest of the air supply line being of 1/4-inch pipe or preferably 3/8-inch tubing.

5. Probe tip design tests showed the inverted $V$-notch design resulted in the lowest plugging rate, with about one half the plugging frequency of the standard straight cut-off design. This improvement noted for the original aluminum nitrate solution did not, however, necessarily hold for all solutions; thus, its overall effect is not as important as the variables discussed above.

6. Where purge gas supply lines are 1/4-inch pipe size or smaller, a sma11 downward slope on any horizontal runs will reduce air binding problems in getting wash water or acid to plugged probes.

7. Solution depth did not show any determinable effect upon plugging frequency.

8. Little or no plugging problems should be encountered with the dilute fluoride, sodium-zirconium blend calciner feed. No serious problem of plugging with the high fluoride, concentrated zirconium waste (plus solid calcium nitrate) should be encountered as long as the purge air does not stop. If the air purge does stop and the solids have a chance to settle, a serious plug may develop. Relatively little probe plugging should occur in the borated cooling water if the boron concentration is held to about $6 \mathrm{gB} / \mathrm{L}$; complete plugging can be expected if the concentration reaches $8 \mathrm{gB} / \mathrm{L}$. Plugs can be expected with the PEW solution, especially on cooling. 


\section{RECOMMENDATIONS}

Based on this study the following recommendations should be implemented:

1. For crystallizing type solutions, keep the solution temperature above the saturation or crystallization temperature.

2. Humidify the purge gas, especially for crystallizing type solutions. This could reduce plugging frequencies by an order of magnitude and thus offers the greatest potential improvement of all the variables studied. Humidification can be accomplished satisfactorily for isolated probes by the use of commercial bubblers such as Meriam Model 931S5, which also allows a quick visual check on purge flows. Humidification for the plant or a major section of the plant would be most efficiently handled by humidifying the purge gas supply to all probes operating at about the same temperature conditions. The actual humidified conditions will depend upon each specific application. Evaporator probes, for example wi11 require much higher humidity than tanks at ambient temperatures; in an evaporator use of low pressure steam to furnish the necessary humidity may be required. The amount of humidification should preferably be only that amount necessary to reduce or prevent deposits from building up on the inside of the probes. By use of reduced purge rates, the amount of dilution effect would be held to a minimum; the importance of this factor will be greatest for the final uranium product storage tanks.

3. Vertical rather than horizontal orientation of the probes should be used, especially on crystallizing type solutions. This will reduce the amount of 1iquid that will wet the inside wal1s of the probe and be subject to drying on the walls. The preferred entrance of purge lines is thus at the top of the tank.

4. The inverted $V$-notch tip probe shape with approximately a 45 degree angle with the horizontal is recommended; use of this probe shape may result in a $50 \%$ reduction in plugging frequency.

5. A $100 \mathrm{~mm}$ (4-inch) Tong enlarged probe of 3/4-inch pipe should be used for probes; this pipe should be welded to the end of 1/4-inch pipe or 3/8-inch tubing purge gas supply line to increase the time required to plug the probe tip, the plugging time being approximately proportional to the probe diameter. The length of purge gas supply line should be under $35 \mathrm{~m}(100 \mathrm{ft})$.

6. Low purge rates of 20 to $100 \mathrm{smL} / \mathrm{min}(0.04$ to $0.2 \mathrm{scfh})$ should be used. A rate of $100 \mathrm{smL} / \mathrm{min}$ through a $3 / 4$-inch pipe size probe gives a Tinear velocity of $0.5 \mathrm{~cm} / \mathrm{sec}$; a rate of $20 \mathrm{smL} / \mathrm{min}$ through a $3 / 8-\mathrm{inch}$ 
tubing probe is equivalent to a linear velocity of $0.7 \mathrm{~cm} / \mathrm{sec}$. The lowest rates will require low purge rate meters below the normal standard purge meters, but substantial reduction in plugging frequency wil1 result.

7. Since the back pressure of the purge gas on probes does not rise appreciably until the passageway is restricted to approximately 1 to $2 \mathrm{~mm}$ diameter, one must rely on alarms on back pressure signals to signify complete plugging of the probe. If the plug is caught immediately, it is sometimes possible to break the plug indication by increasing the purge rate drastically, but it is doubtful that the complete plug would be broken. Thus, water or acid washing of the probe should be carried out each time. If this is not done, replugging can be expected in a much shorter time. Longer contact times with the wash solution will be more efficient in the amount of plug material removed.

8. Horizontal runs of 1/4-inch pipe or smaller purge gas supply lines should be installed with a slight downward slope to assist in reducing air binding and allowing the wash solution to get to the plugged probe more easily.

9. The effective tip of the probe where the purge gas bubble escapes should not be closer than $5 \mathrm{~mm}$ above the bottom of the vessel to avoid end effects upon the bubble that would increase the base-line back pressure. 


\section{REFERENCES}

1. Ayers, A. L., Eurochemic Internal Report No. 106, Minutes of Discussions with Mr. Ayers (ICPP) During his Visit to Eurochemic October 1963, EIR-106 (NP-15019) (1964).

2. Challe, J. and R. Freiwald, "An Experimental Investigation of Level Measurements by Air-Purged Dip-Tubes", ETR-152 (NP-13726) (JuTy 1963).

3. Klitgaard, J., "Slurry Detection by Means of Purged Dip-Tubes", ETR-149, Eurochemic Technical Report (JuTy 1963).

4. Kel1y, M. J., "Get Maximum Accuracy from Your Dip-Tube Level and Density System", Control Engineering 5, No. 8 (August 1958).

5. Long, J. T., "Engineering for Nuclear Fuel Reprocessing", Gordon and Breach, New York (1967).

6. Bianco, E. G. et. al., "Statistical Survey of Pressure Differential Methods in the Determination of Liquid Level and Specific Gravity", ORNL CF 51.9-151 (September 25, 1951).

7. Hicks, T., L. H. Jones, "Purge Line Experiment", American Cyamamid Co., Atomic Energy Division, Idaho Operations (unpublished data) (1953).

8. Foster, W. E. and E. R. Rosa1, "Specific Gravity Instruments for a Nuclear Fuel Reprocessing Plant", WCAP 6033 (December 1959).

9. Rosal, E. R., "Liquid Level Instruments for a Nuclear Fuels Reprocessing Plant", WCAP 6034 (Decmeber 1953). 